\title{
Key steps for effective breast cancer prevention
}

Kara L Britt ${ }^{1,2}$, Jack Cuzick ${ }^{3}$ Kelly-Anne Phillips ${ }^{2,4,5}$

${ }^{1}$ Breast Cancer Risk and Prevention Laboratory, Peter MacCallum Cancer Centre, Melbourne, VIC, Australia.

${ }^{2}$ The Sir Peter MacCallum Department of Oncology, The University of Melbourne, Parkville, VIC, Australia

${ }^{3}$ Centre for Cancer Prevention, Wolfson Institute of Preventive Medicine, Queen Mary University of London, London, UK

${ }^{4}$ Department of Medical Oncology, Peter MacCallum Cancer Centre, Melbourne, VIC, Australia.

${ }^{5}$ Centre for Epidemiology and Biostatistics, School of Population and Global Health, the University of Melbourne, Parkville, VIC, Australia

$\dagger$ Corresponding author:

Kara L Britt.

Kara.britt@petermac.org 


\begin{abstract}
Despite decades of laboratory, epidemiological and clinical research, breast cancer incidence continues to rise. Breast cancer remains the leading cancer -related cause of disease burden for women, affecting 1 in 20 globally and as many as 1 in 8 in high income countries ${ }^{1}$ reducing breast cancer incidence will likely require both a population-based approach of reducing exposure to modifiable risk factors, and a precision-prevention approach of identifying women at increased risk and targeting them for specific interventions, such as risk-reducing medication. We already have the capacity to estimate an individual woman's breast cancer risk using validated risk assessment models, and the accuracy of these is likely to continue to improve over time, particularly with inclusion of newer risk factors, such as polygenic risk and mammographic density. Evidence-based risk-reducing medications are cheap, widely available and recommended by professional health bodies however, widespread implementation of these has proven challenging. The barriers to uptake of, and adherence to, current medications will need to be considered as we deepen our understanding of breast cancer initiation and begin developing and testing novel preventatives.
\end{abstract}

\title{
Introduction
}

In high income countries, breast cancer (BC) mortality is decreasing, largely owing to improved treatments ${ }^{2}$. Conversely, incidence has been steadily increasing ${ }^{3-8}$ due in part to an increase in diagnosis as a result of the implementation of mammographic screening, but also perhaps implying a failure of existing $\mathrm{BC}$ prevention strategies ${ }^{2}$. BC will affect as many as 1 in 8 in high income countries by age 85 and remains the leading cancer -related cause of disease burden for ${ }^{1}$. Prevention potentially offers the most cost-effective strategy for cancer control and would reduce the social impact of BC.

Clinically, specific subtypes of BC are defined by their histopathological appearance and expression of hormone receptors and growth factors (namely the estrogen receptor (ER), the progesterone receptor (PR) and human epidermal growth factor receptor 2 (HER2, also known as ERBB2)). Yet, it is mostly ER positive $\mathrm{BC}$ that is increasing in incidence ${ }^{5,6,9}$. 
Both genetic and non-genetic risk factors influence BC development. Genetic factors include pathogenic mutations in high and moderate risk cancer predisposition genes (e.g. BRCA1 or BRCA2 and checkpoint kinase 2 (CHEK2) respectively) and BC-associated common single nucleotide polymorphisms $(\mathrm{SNPs})^{10}$. Non-genetic risk factors include increasing age, personal history of breast pathologies such as atypical hyperplasia and lobular carcinoma in situ), high mammographic density (MD), exposure to therapeutic chest radiation (e.g. for treatment of Hodgkins disease), high body mass index (BMI), exogenous female hormone use (e.g. menopausal hormone therapy (MHT) and hormonal contraceptives), alcohol, inadequate physical activity, and reproductive factors (early menarche, low parity, shorter breastfeeding periods and late menopause). The population frequency of some of these genetic and non-genetic factors, and their associations with BC risk are shown in Figure 1. The distinction between genetic and non-genetic risk factors is not absolute, as many of the "nongenetic' risk factors may have a genetic component that is yet to be fully elucidated ${ }^{11-13}$.

This review discusses the evidence for the role of risk factors in driving $\mathrm{BC}$ incidence and their integration into tools to estimate $\mathrm{BC}$ risk for an individual woman - the first essential step towards precision prevention. Furthermore, it evaluates existing medications to reduce $\mathrm{BC}$ risk and their associated challenges, as well as outlines the search to find better alternatives. Lastly, learning from the uptake and adherence issues of available medications, it also discusses the priorities that need to be considered when developing and implementing alternatives.

\section{Genetic risk factors}

A high incidence of $\mathrm{BC}$ in certain families was first noted in $1866^{14}$; however the most common $\mathrm{BC}$ susceptibility genes, BRCA1 and BRCA2, were not discovered until the mid $1990 \mathrm{~s}^{15,16} . B R C A 1$ and $B R C A 2$ are involved in the repair of DNA double strand breaks through homologous recombination. Inherited mutations in these genes account for about $2.5 \%$ of all $\mathrm{BCs}$, are responsible for only a minority of BCs in women with a strong family history of the disease ${ }^{17}$ and result, on average, in about a $70 \%$ risk of $\mathrm{BC}$ by age 80 years ${ }^{18}$. That average high risk is modified up or down for an individual mutation carrier by her family history of $\mathrm{BC}$, site of mutation, and other genetic and non- 
genetic factors ${ }^{18}$. Other high and moderate penetrance BC predisposition genes include cadherin-1 ( $C D H 1$; which encodes E-cadherin), PTEN, serine/threonine protein kinase 11 (STK11; also known as $L K B 1), T P 53, C H E K 2$, ataxia telangiectasia mutated $(A T M)$, nibrin $(N B N)$ and partner and localizer of BRCA2 (PALB2), but germline mutations in all of these are rare ${ }^{19}$. However, they are still included on many genetic risk gene testing panels, and additional screening, preventive options and genetic counselling are offered to mutation carriers ${ }^{20}$.

Other much more common low penetrance SNPs also affect BC risk. While they confer small risks individually, their combined effect, when summarised as a polygenic risk score (PRS), can be substantial $^{21-23}$. SNP-based PRS can also be combined with other risk factors in risk prediction models such as breast and ovarian analysis of disease incidence and carrier estimation algorithm (BOADICEA) and IBIS, which incorporate family history, age, genetic and other risk factors ${ }^{24}$. A SNP-based PRS also improves risk prediction in women with pathogenic mutations in rare high and moderate penetrance genes ${ }^{25,26}$. Despite the PRS not being routinely used in clinics, there are large cohorts currently being assessed to see how SNP-based PRS might affect BC risk management in various settings including the WISDOM (Women Informed to Screen Depending On Measures of risk) study ${ }^{27-29}$. Additionally, studies to assess chromatin organization are ongoing to identify the actual genes affected by the BC-associated SNPs, which are often not located (in the nucleotide sequence) close to the genes they most strongly influence ${ }^{30}$.

\section{Non-genetic risk factors}

Whilst obesity and alcohol use both contribute, the increased incidence of ER positive $\mathrm{BC}$ is driven to a large extent by changes in reproductive patterns ${ }^{31-35}$.

\section{Age of menarche and menopause}

Since the mid-19th century the average menarcheal age has decreased from 17 to 12 years of age $^{32,36,37}$. The relative risk (RR) of $\mathrm{BC}$ increases by $5 \%$ for each year younger a women is at menarche ${ }^{38}$. Factors known to affect age at menarche include gestational exposure to cigarette smoke, 
diet, psychological state, maternal weight gain and $\mathrm{BMI}^{39-45}$. Moreover, the inverse association between BMI and menarche timing is particularly strong ${ }^{34}$. In one sequencing study, 30 new genetic loci encoding proteins involved in lipid metabolism and cell growth were shown to be associated with menarche timing ${ }^{46}$. Additionally, separate studies have shown that increased gestational weight gain is associated with a greater chance of obesity in adolescent offspring and excessive maternal weight gain has been shown to lower the age at menarche in daughters ${ }^{34,47,48}$.

Older age at menopause is associated with an increased $\mathrm{RR}$ of $\mathrm{BC}$ of $2.9 \%$ per year of delay when compared to the mean age of natural menopause ${ }^{32,38,49-51}$. The average age of menopause has increased from approximately 49 in $1908^{52}$ to 51.4 now ${ }^{53,54}$. This 2 year increase in age at menopause would instil a moderate $6 \%$ increased RR of BC. Menopause timing is affected by socioeconomic status, parity, use of the oral contraceptive pill (OCP) and smoking ${ }^{55}$. In addition, through mother-daughter and twin studies, it has been demonstrated that $44-63 \%$ of the timing can be accounted for by heritability ${ }^{34}$. Polymorphisms within the ER signaling pathway have also been found, but more work is required to determine what this means for the level of ER signaling ${ }^{56,57}$. Further implicating hormones in menopause timing, women with a later menopause have longer menstrual cycles and the latter is suggested to be related to hormone levels in the follicular phase ${ }^{58}$. Research in pre-clinical models and women where possible should focus on determining why the breast is particularly sensitive to cancer risk if there are changes in hormonal exposure at both the beginning and end of reproductive cycling ${ }^{34}$.

\section{Childbearing}

Women are having fewer children (and often later in life) which also increases BC risk, an association identified in the $18^{\text {th }}$ century when nuns were found to have an increased risk of $\mathrm{BC}^{59}$. Childbearing prior to 35 years of age provides longer term protection against BC with the age of first birth being particularly important. If aged $<20$ years, the longer term RR is reduced by $70 \%$ compared with nulliparous women. As the age at first full term birth increases, the longer-term protection from parity is progressively $\operatorname{lost}^{35}$ and for those women who begin childbearing after age 35 , the risk of $\mathrm{BC}$ is 
higher than for nulliparous women ${ }^{35,60}$. This parity associated protection has been shown to be specific for ER positive $\mathrm{BC}^{61-63}$ but the data related to molecular subtypes of $\mathrm{BC}$ is mixed ${ }^{64,65}$.

In Australia, as in other high income countries ${ }^{66-68}$, fertility rates have dropped to an average of 1.7 children per woman (compared to 3.5 in 1960 and 5 earlier in the $20^{\text {th }}$ century), almost a quarter of women will remain nulliparous ${ }^{69,70}$ and over $60 \%$ of parous women delay childbearing until after age 30 , which provides little or no $\mathrm{BC}$ protection ${ }^{71}$. Older age at first birth is most common among highly educated women ${ }^{69}$ (average age of first birth in the USA in 2017 was 3.5 years older for collegeeducated women ${ }^{72}$ ). These changes in reproductive behaviors and increase in $\mathrm{BC}$ risk are observed globally ${ }^{49,73,74}$.

The protection afforded by pregnancy is not immediate; first there is a period of increased risk as the breast undergoes a post-partum involution process to return to its pre-pregnant state. This takes on average 10 years ${ }^{75}$. Older age of first-time childbearing means that this transient increased RR of BC after birth is more important because baseline BC risk increases with age and also the transient increase is more prolonged in older first-time mothers ${ }^{75}$.

The mechanisms that underlie the protection from BC following childbirth have not been defined. A reduction in the number of mammary stem cells (MaSCs) ${ }^{76}$ and reduced sensitivity to estrogens ${ }^{77}$ have been postulated. MaSCs are thought to be the cells of origin for carcinogenic transformation ${ }^{78,79}$, and therefore, reduced levels of them would leave the breast less susceptible to tumorigenesis ${ }^{80}$. In support of this, the RR of $\mathrm{BC}$ owing to radiation exposure is highest in young women, whom, it is proposed, acquire radiation-induced mutations (environmental exposure or for treatment of other cancer types) in long lived MaSCs ${ }^{81,82}$. Moreover, rat mammary glands are most sensitive to dimethybenz-(a)anthracene (DMBA) induced carcinogenesis in puberty, when terminal end buds (believed to serve as niches for MaSCs) are most abundant ${ }^{79}$. However, mouse studies directly assessing the role of MaSCs in parity protection have provided conflicting results ${ }^{83-85}$ with one study in particular showing that MaSCs are not in fact localized in terminal end buds ${ }^{86}$. 
Our group has recently provided some insight into this controversy by demonstrating that whilst cellular repopulating activity is reduced by parity, it is not due to the classically defined MaSCs (Britt and colleagues unpublished data). Additionally we have also shown that the number of ER positive epithelial cells are decreased by parity leaving the breast less sensitive to the pro-proliferative effects of estrogen ${ }^{77}$. In line with this, Jindal and colleagues have also shown that breast tissue of parous women has reduced proliferation ${ }^{87}$.

The immune microenvironment may also contribute to parity induced protection. However, the relationship is complicated by the fact that protection occurs only after women pass through an increased risk period immediately following the pregnancy as the breast undergoes post-partum involution. During the involution process (first five years post pregnancy in women, and first weeks in mice) there are increased myeloid cells which can dampen the adaptive immune response and lead to a pro-tumorigenic environment ${ }^{75,88,89}$. However, once involution completes parous women are afforded long-term protection against $\mathrm{BC}$. The immune changes that occur in the resting parous women are long-term changes to the breast and may mediate the decreased $\mathrm{BC}$ risk in parous women. Resting parous breast has an enrichment of genes involved in immune-surveillance (SARM1, T cell receptor $\beta(T C R \beta)$, human leukocyte antigen-A24 (HLA-A24) and interleukin-22 receptor subunit $\alpha 2$ (IL22RA2)) when compared to nulliparous postmenopausal glands ${ }^{89,90}$. These genes are instrumental in triggering innate immune responses, activating $\mathrm{T}$ cells, eliciting cytotoxic $\mathrm{T}$ cell anti-tumor immunity, and promoting apoptosis of tumor cells. Further work is needed to align these gene expression changes to the specific protective changes in the immune microenvironment. Understanding these may allow us to begin assessing the potential of therapeutically instilling a protective immune microenvironment.

\section{Breastfeeding}

For every 12 months of breastfeeding, there is a RR reduction for BC of $\sim 4 \%^{31,73,91,92}$. Importantly, the protection conferred by breastfeeding is not limited to ER positive $\mathrm{BC}{ }^{61,93,94}$. The mechanisms of breastfeeding-induced protection are largely unknown; however, glycoproteins stanniocalcin-1 
(STC1) and STC2 are increased during lactation and these in turn inhibit protease pappalysin-1 (also known as PAPP-A), an oncogene that is increased during pregnancy, which along with insulin-like growth factor-binding protein 5 (IGFBP5) stimulates tumour formation ${ }^{95}$.

Current breastfeeding rates are much lower than the recommendation of the World Health Organization (WHO), which calls for breastfeeding only for the first 6 months of life, with continued breastfeeding and complementary foods up until two years of age or beyond ${ }^{96}$. In Australia and the UK respectively, $90 \%$ and $69 \%$ of women initiate exclusive breastfeeding; however $50 \%$ and $23 \%$ of these have ceased by 6-8 weeks ${ }^{97-99}$. Moreover, Victora and colleagues ${ }^{100}$ found that in low-income and middle-income countries, only $37 \%$ of children younger than 6 months of age were exclusively breastfed. Breastfeeding rates and duration could potentially be rapidly increased by scaling up known interventions, policies and programs, such as lactation support programs, reinforcing a breastfeeding culture (e.g. by removing actual and perceived restrictions on breastfeeding in public), adequate paid parental leave, flexible working arrangements and prohibition of aggressive and inappropriate marketing of breastmilk substitutes ${ }^{101}$.

\section{Mammographic density}

MD is the extent of white or radio-opaque tissue (dense area) on a mammogram, and the term percent MD (PMD) is used to represent this dense area as a proportion of the total tissue area of the breast on a mammogram. There are multiple ways to measure MD and controversy exists over the measure that best correlates with BC risk. The Breast Imaging Reporting and Data System (BI-RADS) is the most commonly used tool clinically and includes 4 categories (almost entirely fat, scattered density, heterogeneously dense, and extremely dense $)^{102}$. Limitations of the BI-RAD assessment include that it provides crude categorical estimates of density (rather than a continuous measure) and is reader dependent. There have been 5 BI-RAD editions with the 2017 release including clarification of previous terms to assist with risk stratification ${ }^{103}$. 
Many studies have demonstrated that, after adjustment for age and BMI, MD is an independent risk factor for $\mathrm{BC}$, with a RR ranging from 1.8 to 6.0 in women with high MD (HMD) when compared to those with low MD (LMD) ${ }^{104}$. A systematic review and meta-analysis of 42 studies found that the RRs for BC were 2.92 and 4.64 for women with heterogeneously dense or extremely dense breasts respectively, compared to women with almost entirely fatty breasts ${ }^{104}$. Hopper and colleagues showed that measures of MD may explain more variation in risk across the population than known genetic variants, when adjusted for other risk factors, in particular age and $\mathrm{BMI}^{105,106}$.

HMD is an important $\mathrm{BC}$ risk factor, not only because of the magnitude of the risk with which it is associated, but because it is highly prevalent; $43 \%$ of women in high income countries aged 40-74 have extremely or heterogeneously dense breasts ${ }^{107}$. In the United States (US), this corresponds to more than 27.6 million women. The US and the state of Western Australia are the only places where standardized mammographic reporting includes a MD measure, largely resulting from consumer advocacy campaigns. The lack of routine MD reporting globally may be owing to controversy over which density measure best correlates with risk and a lack of clear clinical pathways for management of women with HMD.

Although generally considered a non-genetic risk factor, twin studies have demonstrated that about $60 \%$ of the variation in MD is explained by genetic factors ${ }^{13}$. The pathobiology underlying HMD is not well understood but recently has been correlated with increased levels of stroma and epithelium ${ }^{108}$ as well as immune cells ${ }^{109}$ compared with LMD (Figure 2).

Lastly, MD is also emerging as a potential biomarker for prevention. A reduction of MD greater than $10 \%$ following treatment with a selective ER modulator (SERM), tamoxifen has been associated with a $63 \% \mathrm{BC}$ risk reduction (odds ratio (OR): 0.37$){ }^{110}$. However, the case for aromatase inhibitors (which reduce post-menopausal estrogen synthesis) is not as strong ${ }^{111}$. The reasons why MD is appealing as a predictive biomarker are that it is strongly associated with endocrine exposure, is noninvasively measured and can be incorporated into routine patient management. Nevertheless before it is introduced we need to determine the change threshold in MD that best predicts improved outcome, 
the most accurate predictive parameter of MD i.e. percent density vs. absolute measures or categorical density (BI-RAD, Boyd or Wolfe) ${ }^{112,113}$ and how we should interpret MD i.e. visual vs. computer assisted vs. fully automated methods.

\section{Overweight and obesity}

High BMI in the post-menopausal years is associated with a significant increase in BC risk, although it appears protective in premenopausal women. Specifically, in an international meta-analysis of 10 studies from 9 prospective cohorts and 22 case control studies, postmenopausal women in the highest body weight categories had an $82 \%$ increased RR for ER positive BC compared with those in the lowest body weight categories; there was no association with the other BC subtypes ${ }^{114}$. Conversely, pre-menopausal women in the highest body weight category had a $20 \%$ lower risk of developing ER positive BCs (similarly, there was no association with the other BC subtypes). Several mechanisms have been proposed to explain the link between increased BMI and cancer risk including increased conversion of androgens to estrogens, insulin and insulin-like growth factor (IGF) signalling, adipokine pathophysiology and chronic inflammation ${ }^{115}$. For BC specifically, the case for hormonal stimulation is supported by in vitro and in vivo experimental data ${ }^{116}$ and the fact that male $\mathrm{BC}$ risk factors (obesity, Klinefelter syndrome and gynaecomastia) are associated with increased estrogen levels ${ }^{117}$.

The Iowa Women's Health and Nurses' Health studies showed that women who maintained or lost weight as they got older had a reduced RR of post-menopausal BC ${ }^{118,119}$. This is supported by earlier epidemiological studies showing $>10 \mathrm{~kg}$ weight loss between $22-44$ years of age was associated with an OR of $0.6^{120}$. Meta-analyses have also confirmed adult weight gain is associated with increased post-menopausal, but not pre-menopausal BC risk ${ }^{121}$. However, it is only those women with BMI of $<23.4 \mathrm{~kg} / \mathrm{m}^{2}$ at age 20 years who had their BC risk influenced by adult weight gain ${ }^{122}$. It is not clear why the $\mathrm{BMI}$ at age 20 impacts postmenopausal $\mathrm{BC}$ risk, but it is postulated to be due to hormonal differences in adolescent girls with high BMI ${ }^{122}$. 


\section{Physical Inactivity}

Independent of BMI - mediated risk reduction, moderate to vigorous physical activity is associated with about a $20 \%$ reduced $\mathrm{RR}$ of $\mathrm{BC}$ when comparing the most to least physically active women ${ }^{123-}$ ${ }^{126}$. Informed by these findings, the World Cancer Research Fund has concluded that physical activity probably protects against $\mathrm{BC}{ }^{127}$. Independent of changes in adiposity, mechanisms that may account for this protection include physical activity effects on estrogen metabolism, insulin sensitivity, chronic low-level inflammation, oxidative stress, and immune function ${ }^{124,126}$. Physical activity-induced transcriptional changes are also possible ${ }^{128,129}$. Experimental studies have also directly addressed why exercise is beneficial. For example, the colony forming ability of non-small-cell lung cancer (NSCLC) cells is reduced by $80 \%$ after pre-incubation with conditioned serum from exercised individuals ${ }^{130}$ and tumour incidence in mice is halved ${ }^{131,132}$. Work is underway to define the molecular signals underlying this. Whilst the optimal level of physical activity necessary for BC prevention is not clear with more than half the population in high income countries (including Australia, UK and the US) not meeting the recommended physical activity guidelines ${ }^{133}$, there are opportunities for improvement.

\section{Alcohol}

Data from the Nurses' Health Study showed that women consuming 5-10 grams of alcohol per day (i.e. 3-6 glasses of wine per week) were 15\% more likely (RR 1.15) to develop BC than non-drinkers, and those consuming at least 30 grams per day (i.e. at least 2 drinks per day) were 50\% (RR 1.50) more likely ${ }^{134}$. Similar results were found in the Million Women Study ${ }^{135}$. A large prospective pooled Australian cohort, Arriaga et al., $2019^{136}$ have recently shown that regular alcohol consumption is the leading modifiable cause of BC burden for premenopausal women, explaining $12.6 \%$ of BCs.

The mechanism by which alcohol (now considered a class I carcinogen by the international agency for research on cancer (IARC)) increases BC risk is an active area of study. Ethanol is known to stimulate cell proliferation and the transcriptional activity of ligand activated ER, which in turn increases levels of circulating estrogen levels ${ }^{137,138}$. Ethanol metabolism takes place mainly in the liver 
where it is oxidized to acetaldehyde by the alcohol dehydrogenase (ADH) enzymes; however, ADH enzymes are also expressed in the breast ${ }^{139}$. Acetaldehyde can induce DNA strand deletions, chromosome aberrations and DNA adducts and is considered mutagenic and carcinogenic ${ }^{140}$. Furthermore, some experimental work has been performed in mice looking at the effects of alcohol on the immune response to cancer ${ }^{141}$. They found that CD8 cytotoxic T cells (which are capable of killing tumour cells) were decreased, in particular the CD8 memory T cells, which allow an efficient anti-tumour response should re-infection occur. Myeloid derived suppressor cells were also increased, which supress $\mathrm{T}$ cell responses and an increase in CD3+ invariant NKT cells that had a protumorigenic expression profile ${ }^{141}$. Overall this suggests that alcohol supresses the ability to the immune system to respond to cancer.

The World Cancer Research Fund and the American Institute for Cancer Research (AICR) report recommends that if alcoholic drinks are to be consumed, that this is limited to no more than two drinks a day for men and one drink a day for women ${ }^{142}$. Although earlier research supported potential health benefits for low to moderate alcohol intake ${ }^{143}$, more recent, methodologically robust research has concluded that the safest level of alcohol intake is none ${ }^{144}$. Alcohol is an ingrained aspect of the culture in many parts of the world. Reducing population intake of alcohol will require government commitments to developing and implementing policies similar to those that have reduced smoking rates in many jurisdictions, such as increased alcohol taxation, control of the physical availability of alcohol and hours of sale and banning alcohol advertising and implementing plain packaging.

\section{Lifestyle}

It is important to note that the benefits of a healthy lifestyle in terms of reducing BC risk are particularly important, in absolute terms, in women at high familial risk of the disease. We have shown that the RR for associations between BC risk factors such as BMI and physical activity are similar regardless of the underlying familial risk; this means that the absolute risk associated with higher BMI or lower physical activity is much greater for women at high familial risk compared with those at population risk ${ }^{145,146}$. Therefore, it is crucial that the larger potential benefits for lifestyle 
changes are explained to women at increased risk who may otherwise feel that the familial factors are so overwhelming that there is little to be gained by lifestyle adjustment. Unfortunately, there is very limited interventional trial data on lifestyle changes. However, one study, the women's health initiative (WHI) dietary modification trial, showed that reduced fat intake and increased consumption of vegetables, fruits and grains led to a $5 \%$ reduction in $\mathrm{BC}$ risk (Hazards ratio (HR): 0.95) at the long-term follow-up (19.6 years) ${ }^{147}$. Further well designed lifestyle intervention trials assessing impacts on $\mathrm{BC}$ risk are needed and will surely help to convince those at risk of the impact these changes could have on their personal risk.

\section{$\mathrm{BC}$ risk in diverse populations}

The National Cancer Institute (NCI)'s Surveillance, Epidemiology, and End Results (SEER) program showed that in the U.S. the age-adjusted BC incidence for ethnic minorities was lower than those for white women, with 141 cases per 100000 in white women, 122 in African Americans, 97 in Asian and Pacific Islanders, 90 in Hispanics, and 58 in American Indians and Alaskan Natives ${ }^{148}$. The difference in risk factors across the ethnicities and the use of screening mammography could explain some of the differences, but BC incidence was still significantly lower in African Americans than whites when adjusted for these differences ${ }^{148}$. Despite the lower overall incidence, African American women are more likely to be diagnosed with advanced and largely ER negative BC compared with white women ${ }^{149}$. Whilst the reason for these differences is not fully understood, it may involve the known associations between certain risk factors and disease subtypes. For example, multiparity and early first pregnancy protect against $\mathrm{ER}+$ luminal $\mathrm{BC}$, but do not protect against the development of basal-like breast cancer ${ }^{62,150}$

Heritability analyses show that $\mathrm{BC}$ is a highly polygenic disease ${ }^{151}$. In addition to the rare, high risk alleles, there are common variants with a small effect on risk (Figure 1). The use of a PRS assessing the effects of these variants on risk has only been thoroughly validated in European populations. Only the Breast Cancer Risk Assessment Tool (BCRAT) from the national institutes of health (NIH) has been validated for use in black or African American women, Hispanic women and Asian and Pacific 
Islander women ${ }^{152-154}$. Genome wide association studies (GWAS) in multiple ethnicities such as the National Cancer Institute led Confluence project (300,000 BC cases and 300,000 controls) will drive a better understanding of the etiology of $\mathrm{BC}$ and allow us to improve risk stratification across ancestry groups.

\section{[H1] Predicting BC risk}

A key component of optimal precision prevention is the capacity to accurately estimate a woman's $\mathrm{BC}$ risk. This facilitates the use of evidence-based prevention interventions appropriate to the woman's personal risk level. It also enables calculation of the absolute risk-reduction from preventive interventions, thus assisting informed decision making.

$\mathrm{BC}$ risk estimation models now exist which attempt to quantify the combined effect of many of the $\mathrm{BC}$ risk factors discussed above ${ }^{155}$. Many of these have not undergone independent validation in study populations other than those used in their development and will not be considered further here. The independently validated models vary regarding the risk factors they utilise. The risk factor inputs for some of the main models are shown in Table $1^{156-169}$.

Of the validated models, most ${ }^{156,157,159,166,170-174}$, but not all ${ }^{160,167-169,175}$, incorporate non-familial risk factors to varying degrees. The IBIS model encompasses the most comprehensive list of risk factors and performs well in comparative validation studies ${ }^{158,176-179}$. Polygenic risk to SNPs has been shown to predict $\mathrm{BC}$ risk almost independently of other factors, including $\mathrm{MD}^{179}$, and the IBIS model is the only validated, widely available model that currently incorporates polygenic risk ${ }^{179,180}$.

The performance of risk prediction models is often measured based on their discriminatory accuracy and calibration. The performance of the various BC risk prediction models varies, with discriminatory accuracy ranging from 0.56 to 0.71 (poor to good) ${ }^{181}$ and calibration ranging from 0.85 to 1.52 according to a recent systematic review ${ }^{182}$. Work is ongoing to improve the accuracy of these risk 
prediction models. For example, common risk prediction models do not currently include some modifiable risk factors such as alcohol, hormonal contraception use, physical activity or time since last pregnancy. It will also be important to determine if additional, more novel risk factors, such as steroid hormone levels (e.g. estradiol and testosterone) ${ }^{183}$, epigenetic markers ${ }^{184}$ and double-strand DNA repair phenotype ${ }^{185}$, will give maximal improvement to the models. Incorporation of new risk factors into existing models will require consideration of potential interactions with existing risk factors and extensive validation, preferably using prospective data.

The current models have other limitations besides their limited discriminatory accuracy. Firstly, the models tend to have different performance characteristics depending on the subset of women they are applied to, but many clinicians are not skilled in choosing the most appropriate risk model, nor do clear guidelines exist ${ }^{186}$. A related issue is that the models have been developed and validated largely in populations of European descent, so their accuracy in estimating BC risk for women of other ethnicities is uncertain. Importantly, none of the major validated risk estimation models couple the risk estimation to comprehensive, personalised $\mathrm{BC}$ prevention and screening advice, nor estimation of the absolute risk reduction that can be achieved. And lastly, most have user interfaces that are difficult for women and less experienced clinicians to use. We have recently developed iPrevent ${ }^{187}$ to overcome these issues and to facilitate collaborative decision making about BC risk management, between women and their clinicians. Women can complete the tool online at home and print the output for discussion with their clinician. It has been independently validated, is well calibrated and has good discriminatory accuracy $(0.70$ overall and 0.74 for women under age 50$){ }^{188}$. It has good acceptability and usability for both women and clinicians and seems to improve the accuracy of risk perception without adversely affecting anxiety ${ }^{189}$.

To date, all of these BC risk models have generally been used on an ad hoc basis and to our knowledge, there has been little consideration of population-based risk assessment followed by targeted risk reduction, despite the potential of precision prevention to reduce $\mathrm{BC}$ incidence. 
Targeted risk reduction might include modifying specific risk factors (such as alcohol intake, use of MHT and hormonal contraceptives, physical inactivity and obesity) contributing to each woman's personal risk and, for some women at higher risk, consideration of risk-reducing medication. It is known that consumers find the constant information about BC risk factors in the media and other sources confusing, and are often uncertain how it pertains to them as individuals, with many having expressed a preference for more targeted information ${ }^{190}$. In Australia, formally assessing BC risk at the time of (free, government-funded) breast screening in order to risk stratify women for different screening approaches is currently being considered. However, given that breast screening usually starts at age 50, such an approach would provide no opportunity to prevent the approximately $20 \%$ of BCs that occur before that age ${ }^{191}$. We suggest that consideration should be given to routine risk assessment of women in the general population in early adulthood (and at regular intervals thereafter, given that risk factors change over time). Nevertheless it will be important to 1) identify a risk assessment tool that is accurate and easy to use, 2) show that such risk assessment results in behavioural change and uptake of risk-reducing medication that will reduce $\mathrm{BC}$ risk without increasing anxiety beyond acceptable thresholds, and 3) determine the cost, suitability and feasibility of such an approach in different healthcare systems and among different subgroups (e.g. by ethnicity, age and socioeconomic status).

\section{Currently Available Preventive Options}

Women at increased risk of $\mathrm{BC}$ have several options to reduce their risk, including surgery, medication and lifestyle options (the last is also relevant to women at moderate risk). Table 2 summarises the major US and UK guidelines ${ }^{192-194}$.

\section{Risk-Reducing Bilateral Mastectomy}

The most effective measure for reducing $\mathrm{BC}$ risk is bilateral mastectomy, although guidelines recommend limiting this to women at substantially increased risk. There are no randomised trials of this intervention, but observational studies show it is associated with a $90 \%$ reduction in risk ${ }^{195,196}$. Immediate breast reconstruction is usually offered, although it is associated with much higher rates of 
unanticipated reoperations. Most women are satisfied with their decision to have bilateral riskreducing mastectomy and have a significant reduction in worry-associated with getting $\mathrm{BC}$, but there is less satisfaction with cosmetic results, body image, and sexual feelings ${ }^{197}$. Risk-reducing mastectomy that spares the nipple has better cosmetic outcomes than simple or skin-sparing mastectomy, and limited data suggests it confers similar risk reduction ${ }^{198}$. Uptake of risk-reducing bilateral mastectomy in high risk women is highly variable, with high uptake rates in the US, UK, Netherlands and Norway and low rates in Poland and France ${ }^{199}$.

\section{Bilateral Salpingo-oophorectomy}

Bilateral salpingo-oophorectomy is effective at reducing the risk of cancers of the ovary and fallopian tube. $B R C A 1$ and $B R C A 2$ mutation carriers are generally counselled to consider this procedure by the age at which their ovarian and fallopian tube cancer risk increases above that of the general population, that is by late 30 s (for BRCA1 carriers) and late 40 s (for BRCA2 carriers) ${ }^{18}$. Historically these women have also been counselled to consider the procedure at an earlier age (after childbearing) in order to reduce $\mathrm{BC}$ risk. Randomised trial data on the efficacy of bilateral salpingo-oophorectomy in reducing $\mathrm{BC}$ risk are not available. Earlier studies suggested a halving of $\mathrm{BC}$ risk for mutation carriers who underwent risk-reducing salpingo-oophorectomy (RRSO) ${ }^{200}$; however issues related to the methodology used in this study have been raised ${ }^{201}$. Furthermore, recent prospective cohort studies have found no convincing overall association between RRSO and $\mathrm{BC}$ risk in BRCAl or BRCA2 mutation carriers ${ }^{202-204}$.

\section{Lifestyle Modification}

Modification of non-genetic risk factors, such as obesity, alcohol use and lack of physical activity is an important component of $\mathrm{BC}$ prevention. In general, these non-genetic risk factors confer similar RRs of $\mathrm{BC}$ in high risk women as for those in the general population ${ }^{205}$. Unfortunately, lifestyle modification can be difficult to achieve and sustain. Therefore, focus on the development of efficacious interventions for behavioural change as well as government policies, as already discussed, to support healthy lifestyles will be essential. 


\section{Clinically Available Risk Reducing Medication}

Risk reducing medication is an important prevention option for women at increased risk of $\mathrm{BC}$ who do not wish to undergo (or who wish to postpone) risk-reducing mastectomy or whose risk is increased but not elevated enough for surgery to be considered appropriate. The risk-reducing medications recommended in international guidelines are the selective ER modulators (SERMs), tamoxifen and raloxifene, and the aromatase inhibitors, exemestane and anastrozole (see Table 2). None of these have been shown to reduce $\mathrm{BC}$ mortality and all of them are only able to reduce risk of ER positive BC. Nevertheless, ER positive BC is the most common type and avoiding a BC diagnosis and subsequent treatment, even if that $\mathrm{BC}$ was not going to result in premature mortality seems a worthwhile goal in terms of reducing burden on the healthcare system, women and their families.

Tamoxifen is the best studied risk-reducing medication and is the only preventative agent that has been demonstrated to be effective in pre- and post-menopausal women. It reduces ER-positive BC risk by $33 \%^{206}$, with the risk reduction seen not only during the 5 years whilst taking the medication, but also for at least 15 years after cessation ${ }^{207}$. Reductions in MD in tamoxifen users correlate with its preventive efficacy ${ }^{110}$. However, side-effects of tamoxifen can include menopausal symptoms, such as hot flushes, and a doubling of the risk of thrombosis, although the absolute risk remains low, particularly in younger women ${ }^{208}$. Tamoxifen also doubles the risk of endometrial cancer in postmenopausal women, although again the absolute risk is small ${ }^{208}$. Another major impediment to uptake of tamoxifen by pre-menopausal women for a 5 year period is the inability to prescribe it safely in women who are trying to conceive, who are pregnant or who are lactating and the fact that women need to use a non-hormonal form of contraception ${ }^{209}$.

Another SERM, raloxifene has only undergone trials in postmenopausal women. Raloxifene (60mg daily for 5 years) was compared directly with tamoxifen (20mg daily for 5 years) in the STAR trial and at the 81 month median follow-up raloxifene was only $76 \%$ as effective at reducing ER-positive BCs compared with tamoxifen, but without the increased endometrial cancer risk seen with tamoxifen and with fewer thromboembolic events ${ }^{210}$. Risks and benefits of treatment with raloxifene or 
tamoxifen in post-menopausal women depend on age, ethnicity, BC risk, and hysterectomy status. Tables have been published for both tamoxifen and raloxifene that can help identify groups of women for whom the benefits of these risk-reducing medications outweigh the risks ${ }^{211}$.

Randomised controlled trials of the aromatase inhibitors exemestane and anastrozole have also shown that these medications can reduce BC risk by $60 \%$ at median 2.5 years follow-up and $49 \%$ at median 10.9 years follow-up, respectively ${ }^{212-214}$. These medications can only be used in post-menopausal women as they are ineffective in women with functioning ovaries.

Despite the clear benefits of risk-reducing medication, uptake is low among women at increased risk $^{215,216}$. The reasons are complex and both clinician and patient-related. There is lack of clarity over the most appropriate type of clinician to initiate discussions about risk reducing medications ${ }^{186,215}$, in addition to clinicians having difficulty using the existing risk assessment models ${ }^{215,217}$, and preferring to have a tool that links risk assessment with risk management ${ }^{217}$. Furthermore, clinicians often lack deep knowledge about prevention medications ${ }^{218-220}$ and are concerned over the lack of surrogate markers for the effectiveness of preventive medications as well as the overall lack of commercial interest in prevention ${ }^{215}$. The latter concern comes about because all current prevention medications were off-patent by the time their role in prevention was proven. Thus, unlike newer patented drugs, where companies have a commercial incentive and spend considerable proportions of their budget educating clinicians about their drug, there is no investment to educate clinicians about implementing these older generic prevention medicines into their practice. Additionally, in some countries/regions in Europe and in Australia, there is lack of a clear pathway for regulatory approval of repurposed, offpatent drugs. Tamoxifen was shown to reduce BC risk in $1998^{221}$, and was promptly approved by the US food and drug administration (FDA) for primary prevention but in Australia regulatory approval was not sought until 2016 and only then after substantial advocacy by clinicians and consumer groups. Lack of regulatory approval in Australia before 2016 was a factor in the low rate of tamoxifen prescriptions $^{218}$. 
The major patient factor contributing to low uptake of risk-reducing medications is said to be fear of side-effects ${ }^{222,223}$. However, in the main prevention trials, fewer than $5 \%$ of women ceased treatment because of side-effects ${ }^{213,214,221,224}$. Clinician recommendation and the way clinicians frame information about side-effects is important. For example, regarding the risk for endometrial cancer for post-menopausal women, it may be better to frame the risk as "approximately 996 in every thousand women can take tamoxifen for 5 years without getting endometrial cancer", rather than "your risk is doubled". Few online tools are available currently to help clinicians balance absolute benefits against absolute risks for individual women ${ }^{187}$. Clinicians should also be sure to convey not only potentially adverse side-effects, but also beneficial ones, such as, for example, the potential for decreased breast tenderness, lighter menstrual periods, better bone density and lower cholesterol for women considering tamoxifen use. Clinicians should also consider offering women a short trial of 6-8 weeks of risk-reducing medication to assess their tolerance and so that women do not feel they are committing to a 5 year course with no knowledge of how well they, as an individual, will tolerate the drug. If such a short trial also had a biomarker of effectiveness, it may assist women in drug adherence.

Other patient factors that limit uptake of tamoxifen for ER-positive BC risk-reduction include the fact that it is a cancer drug, the experience of others (usually those with cancer), and the tablet being a daily reminder of their increased cancer risk; although the latter can presumably also work in reverse, with some women reassured by the daily tablet that they are actively reducing their $\mathrm{BC}$ risk ${ }^{222}$. Importantly it has also been shown that women often confuse tamoxifen with chemotherapy, and this has led to recommendations that the word 'chemoprevention' should be avoided ${ }^{222,225}$ with 'riskreducing medication' seemingly a more appropriate term.

\section{Developing novel preventive agents}

The 'perfect' risk-reducing medication would be highly efficacious, have minimal adverse side effects but potentially several beneficial ones, and be able to be used even if on hormonal contraception or during pregnancy or when lactating. It could potentially be a long-acting depot preparation, avoiding 
the need for a daily tablet, and would not be associated in the public mind with a cancer drug. It would be inexpensive and preferably developed in a way that facilitated rapid regulatory approval and engagement of the pharmaceutical industry in implementation. Ongoing trials of $\mathrm{BC}$ prevention medications are summarised in Table 3.

One tactic to provide a new approach to risk-reducing medication that has fewer adverse side-effects than current agents is to modify the dose and delivery system of available agents. Tamoxifen is largely a pro-drug that is metabolised to its active metabolites, including endoxifen, by hepatic enzymes (e.g. cytochrome P450 2D6 (CYP2D6)) ${ }^{226}$. Biomarker studies have suggested that $5 \mathrm{mg}$ per day is equivalent to the usual $20 \mathrm{mg}$ per day dose in inhibiting BC proliferation ${ }^{227}$, suggesting that low dose tamoxifen might be efficacious for prevention. Furthermore, a recent multicentre, randomised trial suggested that a lower dose and duration of tamoxifen (5mg daily for 3 years) might have similar BC prevention efficacy as the usual $20 \mathrm{mg}$ daily for 5 years dose, with fewer side-effects. Unfortunately, these 2 tamoxifen regimens were not compared against one another but, based on this $\operatorname{trial}^{228}, 5 \mathrm{mg}$ of daily tamoxifen for 3 years is now a reasonable BC prevention option for women who do not tolerate dosing at $20 \mathrm{mg}$. It will be important to assess whether this smaller dose for a shorter duration provides the same long-term risk-reduction as 20mg daily for 5 years and whether CYP2D6 status affects the efficacy of the smaller dose. Another approach to potentially reduce the side-effects of tamoxifen is transdermal therapy which can result in high drug concentrations in the breast, but low systemic exposure. A window of opportunity trial in patients with ER positive ductal carcinoma in situ (DCIS) (NCT00952731) ${ }^{229}$ showed oral and transdermal delivery both decreased (by 50-60\%) expression of the proliferation marker Ki67. Atossa Genetics recently announced the results of a phase II study of daily topical endoxifen applied to the breasts, which showed reductions in MD in women using the transdermal medication, with no difference in menopausal side-effects between the topical endoxifen and placebo groups, although the duration of treatment was limited by skin rash. Metformin is a drug that is commonly used to treat type 2 diabetes ${ }^{230}$. Metformin users have a decreased incidence of cancer, and more long-term use ( $\geq 5$ years) is associated with a reduced, adjusted OR of 0.63 for developing $\mathrm{BC}^{231}$. This, and promising pre-clinical work has led to the phase 
III randomized control trial (the PLOTINA study EudraCT Number 2009-009921-28) ${ }^{232}$, comparing metformin versus placebo in post-menopausal women at high risk of type 2 diabetes.

Bisphosphonates, originally used as a treatment for osteoporosis, have been shown in pre-clinical studies to inhibit BC proliferation and metastasis and have been proposed as $\mathrm{BC}$ preventives ${ }^{233-236}$. They are currently used in patients with metastatic BC to reduce skeletal-related events, and their use in the adjuvant setting in post-menopausal women reduces mortality ${ }^{237}$ and is recommended in North American and European guidelines ${ }^{238,239}$. Women who take bisphosphonates for bone density have reduced BC incidence (20-47\% lower depending on the study $)^{234,240}$ suggesting a possible role in BC prevention. Conversely, they do not reduce contralateral BC risk when given adjuvantly ${ }^{237}$. An interventional prevention trial is underway (NCT02781805) ${ }^{229}$ assessing the effects of the bisphosphonate, alendronate, on mammary epithelial cell differentiation and immune cells in high risk women.

Retinoids are another class of drugs that are currently in BC prevention trials (EudraCT Number 2009-010260-41 and NCT03323658) ${ }^{229,241}$. Retinoids are anti-proliferative, cyto-differentiating and apoptotic through their activation of the nuclear hormone retinoic acid receptor $\alpha(\operatorname{RAR} \alpha), \operatorname{RAR} \beta$ and RAR $\gamma$. Strong data in pre-clinical models using the retinoid fenretinide ${ }^{242}$ led to a phase III prevention trial in the late 1980s. Fenretinide showed a trend for reducing the incidence of second primary BCs in premenopausal women (HR: 0.66 and HR: 0.65 for contralateral and ipsilateral BC respectively), which was maintained at 15 -year follow-up ${ }^{243}$. This drug has a very low toxicity profile (mainly reversible skin dryness and rashes as well as difficulties adapting to darkness) which are often overcome by a monthly weekend suspension of the drug. However, it is not safe for pregnant women and so has similar reproductive contraindications in pre-menopausal women as tamoxifen. Yet, the results of these novel $\mathrm{BC}$ preventative trials are eagerly awaited.

Medical prevention of $\mathrm{BCs}$ in BRCA1 mutation carriers has been controversial. These women usually develop ER negative BC, and existing prevention agents have not reduced ER negative BC in clinical 
trials, although observational data in the secondary prevention setting ${ }^{244,245}$ show that tamoxifen is associated with reduced contralateral $\mathrm{BC}$ risk. There is growing evidence suggesting that receptor activator of nuclear factor-kB (RANK; also known as TNFRSF11A) and its ligand (RANKL) play a pivotal role in the development of $B R C A l$ mutant-associated tumors. $\mathrm{RANK}^{+}$luminal progenitors are increased in pre-neoplastic tissue of BRCAl mutation carriers compared with non-mutation carriers ${ }^{246}$. Moreover, these cells have been identified as the cell of origin for the basal-like BC that develop in BRCAl mutation carriers. Pre-clinical studies in Brcal-deficient mice targeting these cells with the RANKL inhibitor (and osteoporosis drug) denosumab successfully inhibited tumour development ${ }^{247}$. Preliminary data from a preclinical window study to evaluate the biological effects of the denosumab on breast tissue biopsies from BRCAl mutation carriers showed proliferation was markedly reduced $^{246}$. An international phase III randomised trial of denosumab is testing whether administering denosumab once every 6 months for 5 years will reduce $\mathrm{BC}$ incidence in $B R C A 1$ mutation carriers (EudraCT Number: 2017-002505-35) $)^{248}$.

There is also interest in anti-progestins (synthetic progestogens) for $\mathrm{BC}$ prevention. Treatment of BRCAl deficient mice with the progesterone antagonist mifepristone inhibits tumorigenesis ${ }^{249}$. Mifepristone is considered too toxic to move into the prevention setting, but other less toxic progesterone receptor modulators are under investigation $(\mathrm{NCT} 02408770)^{250}$. Aspirin, other nonsteroidal anti-inflammatory drugs (NSAIDs), and the statins are inexpensive, widely available and relatively safe drugs, making their potential repurposing for BC prevention an attractive strategy. Whilst mature, randomised trial data are not available for any of these agents in the BC primary prevention setting, at a dose of $\geq 2$ times per week aspirin use for 5 years was associated with reduced BC risk (RR: 0.86), with decreasing risk with longer duration (RR: 0.73 for 10 years and RR: 0.54 for 20 years $)^{251}$. Similar results are observed with another type of NSAID, the cyclooxygenase 2 (COX2) inhibitors ${ }^{252}$. Recent work assessing these associations in a cohort enriched in women with a strong family history showed regular aspirin was associated with a 37-39\% reduction in BC risk, whilst for COX2 inhibitors it was $61-71 \%{ }^{253}$. Some studies have found that aspirin and COX2 inhibitors reduce both ER positive and ER negative $\mathrm{BC}^{253}$ whilst in others only ER positive $\mathrm{BC}$ was reduced $\mathrm{d}^{254-256}$. 
Large scale, randomised controlled trials with both population risk women and those at higher risk are needed to define the true benefits of long-term aspirin use in the preventative setting.

For all of these preventatives, a major task will be determining the best timing of preventative therapy. It is possible that preventive therapy may be delivered immediately prior to the age dependent increase in risk of hormonal BCs or the likely age of onset for familial cancers. This would drive high protection levels during the most crucial time. The 96-month follow-up of the randomized IBIS-I trial showed that 5years of taxoxifen prevention provided better protection in late premenopausal women (35-50 years old) rather than women 50 years or older (RR: 0.65 vs RR: 0.79 ) ${ }^{257}$. Instead, aromatase inhibitors offer an attractive alternative for postmenopausal women. However, as the time between puberty and first pregnancy is known to be a window of risk ${ }^{34}$, ongoing work should determine why this period is so important and if it is also the most effective time to deliver long-lasting preventative therapy. Prevention trials are, by their very nature, quite lengthy and thus clinical trials assessing the impact of new therapies on early breast lesions (such as, hyperplasia and in-situ carcinoma) can be informative when assessing efficacy.

A deeper understanding of the earliest steps in $\mathrm{BC}$ development will aid in our quest to develop novel preventatives. The normal breast epithelium contains numerous cell types and is imbedded within a dense stromal and immune microenvironment ${ }^{258,259}$. Epithelial changes occur in BRCAl mutation carriers at risk of $\mathrm{BC}^{246}$ and it is possible that other epithelial cell subtypes may be increased under alternate risk conditions (Figure 3). Additionally, the stromal and immune microenvironments play a significant role in the growth and progression of pre-invasive and invasive $\mathrm{BC}^{258,260}$ and can stimulate tumour development in the normal post-partum breast ${ }^{88}$. The microenvironment of early lesions and breasts at risk of cancer should be studied in order to determine whether these cells can be targeted for BC prevention (Figure 3).

\section{Conclusions and perspective}


To date, $\mathrm{BC}$ prevention in most parts of the world, has largely focused on untargeted, populationbased educational interventions (such as, increasing physical activity and reducing BMI and alcohol intake). This will remain an appropriate component of $\mathrm{BC}$ prevention, as these interventions also reduce risk of other important causes of morbidity. However, we are moving towards the ability to augment this approach with systematic targeting, or precision prevention. Precision BC prevention will mean delivering the right risk-reducing intervention, at the right time, to the right woman. A vital starting point will be to have a systematic and accurate method of assessing each individual woman's $\mathrm{BC}$ risk. Risk assessment models currently exist and their accuracy will continue to improve. Developing better risk assessment algorithms for specific BC subtypes that are validated in ethnically diverse populations is a high priority. Having a user friendly interface that enables women and clinicians to identify and manage risk will be important in implementing risk management. Implementation researchers and policy-makers should consider how models can be applied to populations in order to ensure that women at increased risk are identified at an early age while there is still time to effectively reduce their risk with existing proven interventions. To efficiently deliver this we will need to define which treatments can be given at which ages for maximal protection. Preclinical studies will be informative in determining such dosing regimens. The treatments will also need to be well tolerated as they are being used in otherwise healthy individuals. Ultimately it is hoped that risk assessment models might one day predict not only whether a woman will or will not develop $\mathrm{BC}$ but at what age, so that risk-reducing interventions can be applied in the most appropriate timeframe. The perfect intervention may target all molecular subtypes of BC, but given their different etiologies, this is unlikely, so models that predict subtype and thus enable the application of future medications that target particular subtypes would be optimal.

As we move to find preventative therapies that do not rely on disrupting estrogen activity, we need to understand more about what drives increased BC risk. Assessing the pre-neoplastic breast tissue of women at increased risk of basal-like $\mathrm{BC}$ ( $B R C A l$ mutation carriers) led to the identification of the cell of origin and the first cell-specific potential BC preventative (Figure 3). Now we need to ask how BRCA2 mutation status alters the breast epithelial hierarchy and if this can be targeted for 
preventative therapies. Furthermore, how do BMI, age and reproductive factors alter breast epithelial cells. If we find that aberrant control of distinct populations of breast epithelial cells are responsible for the generation of the different $\mathrm{BC}$ subtypes (such as for $\mathrm{RANK}^{+}$luminal progenitors and basal-like BC), the development of new preventives may need to be subtype specific.

In the 20th century, the eradication or control of many deadly communicable diseases transformed human health ${ }^{261}$. It is not impossible to imagine that, with the augmentation of our existing BC prevention toolbox with future discoveries, we could achieve the same for $\mathrm{BC}$ in the $21^{\text {st }}$ century. By focusing on the risk factors for $\mathrm{BC}$ and their incorporation into effective risk estimation tools we will identify those women at increased risk. Research into the mechanisms underlying risks will be instrumental in driving the development of therapies to effectively counter or manage those risks and prevent $\mathrm{BC}$ where we can. It is unlikely we can reverse the reproductive choices that are driving hormonally responsive $\mathrm{BC}$; however, public health awareness and preventative therapies will be important, as will a focus on the development of improved hormonal therapies (MHT and OCP) that deliver symptom control and contraceptive benefits, but without increasing BC risk. Whilst this may begin in high income countries a global move to prioritize women's health is required. 
Table 1: Comparison of model inputs for major breast cancer risk estimation models

\begin{tabular}{|c|c|c|c|c|c|}
\hline \multirow[b]{2}{*}{ Model input } & \multicolumn{5}{|c|}{ Risk Estimation Model } \\
\hline & $\operatorname{BCRAT}_{6}^{159,164,16}$ & IBIS $_{5}^{156,158,16}$ & $\operatorname{BRCAPRO}_{7}^{160,162,16}$ & $\mathrm{BCSC}_{1}^{157,16}$ & BOADICEA $_{9}^{163,168,16}$ \\
\hline \multicolumn{6}{|c|}{ Individual factors } \\
\hline Age & $\geq 35$ & $\sqrt{ }$ & $\checkmark$ & $\sqrt{ }$ & $\sqrt{ }$ \\
\hline $\begin{array}{l}\text { Race or } \\
\text { ethnicity }\end{array}$ & $\checkmark$ & $\checkmark$ & $\sqrt{ }$ & $\checkmark$ & $\checkmark$ \\
\hline $\begin{array}{l}\text { Age at } \\
\text { menarche }\end{array}$ & $\sqrt{ }$ & $\checkmark$ & NA & NA & NA \\
\hline $\begin{array}{l}\text { Age at } \\
\text { menopause }\end{array}$ & NA & $\checkmark$ & NA & $\overline{N A}$ & NA \\
\hline Age at $1^{\text {st }}$ birth & $\checkmark$ & $\checkmark$ & NA & NA & NA \\
\hline Parity & NA & $\checkmark$ & NA & NA & NA \\
\hline BMI & NA & $\checkmark$ & NA & NA & NA \\
\hline $\begin{array}{l}\text { Hormonal } \\
\text { contraception } \\
\text { use }\end{array}$ & NA & NA & NA & NA & NA \\
\hline MHT use & NA & $\checkmark$ & NA & NA & NA \\
\hline Alcohol use & NA & NA & NA & NA & NA \\
\hline \multicolumn{6}{|c|}{ Breast-related factors } \\
\hline $\begin{array}{l}\text { No. of prior } \\
\text { breast biopsies }\end{array}$ & $\sqrt{ }$ & $\checkmark$ & NA & $\sqrt{ }$ & NA \\
\hline $\begin{array}{l}\text { Atypical } \\
\text { hyperplasia }\end{array}$ & $\checkmark$ & $\checkmark$ & NA & NA & NA \\
\hline LCIS & $\mathrm{NA}$ & $\checkmark$ & $\overline{N A}$ & $\overline{N A}$ & NA \\
\hline $\begin{array}{l}\text { Other benign } \\
\text { pathology }\end{array}$ & NA & $\checkmark$ & NA & NA & NA \\
\hline $\begin{array}{l}\text { Mammographi } \\
\text { c density }\end{array}$ & NA & $\sqrt{ }$ & NA & $\sqrt{ }$ & NA \\
\hline $\begin{array}{l}\text { Therapeutic } \\
\text { irradiation* }\end{array}$ & $\overline{N A}$ & NA & NA & $\overline{N A}$ & NA \\
\hline \multicolumn{6}{|l|}{ Genetic testing } \\
\hline $\begin{array}{l}\text { BRCA1 or } \\
B R C A 2\end{array}$ & $\overline{N A}$ & $\checkmark$ & $\sqrt{ }$ & NA & $\checkmark$ \\
\hline $\begin{array}{l}\text { Other high risk } \\
\text { genes }\end{array}$ & NA & NA & NA & $\overline{N A}$ & $\checkmark$ \\
\hline $\begin{array}{l}\text { SNPs or } \\
\text { polygenic risk } \\
\text { score** }\end{array}$ & NA & $\checkmark$ & NA & NA & $*$ \\
\hline \multicolumn{6}{|l|}{ FHx factors*** } \\
\hline $\begin{array}{l}\text { Cancer status } \\
\text { of } 1 \text { st degree } \\
\text { relatives }\end{array}$ & $\checkmark$ & $\checkmark$ & $\checkmark$ & $\checkmark$ & $\checkmark$ \\
\hline $\begin{array}{l}\text { Cancer status } \\
\text { of } 2^{\text {nd }} \text { degree } \\
\text { relatives }\end{array}$ & $\overline{N A}$ & $\checkmark$ & $\sqrt{ }$ & NA & $\sqrt{ } * *$ \\
\hline $\begin{array}{l}\text { Age at BC } \\
\text { diagnosis }\end{array}$ & NA & $\checkmark$ & $\checkmark$ & $\overline{N A}$ & $\checkmark$ \\
\hline $\begin{array}{l}\text { Pathology of } \\
\text { BC }\end{array}$ & NA & NA & $\sqrt{ }$ & $\overline{N A}$ & $\checkmark$ \\
\hline Bilateral BC & NA & $\checkmark$ & $\checkmark$ & NA & $\checkmark$ \\
\hline Male BC & NA & $\checkmark$ & $\checkmark$ & NA & $\checkmark$ \\
\hline Ovarian cancer & NA & 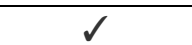 & $\checkmark$ & NA & $\checkmark$ \\
\hline $\begin{array}{l}\text { Pancreatic and } \\
\text { prostate cancer }\end{array}$ & $\mathrm{NA}$ & $\mathrm{NA}$ & NA & NA & $\checkmark$ \\
\hline
\end{tabular}




\begin{tabular}{|l|c|c|c|c|c|}
\hline Genetic testing & NA & $\checkmark$ & $\checkmark$ & NA & $\checkmark$ \\
\hline $\begin{array}{l}\text { Mastectomy } \\
\text { status }\end{array}$ & NA & NA & $\checkmark$ & NA & NA \\
\hline $\begin{array}{l}\text { Oophorectomy } \\
\text { status }\end{array}$ & NA & NA & $\checkmark$ & NA & NA \\
\hline
\end{tabular}

BC, breast cancer; BCRAT, breast cancer risk assessment tool; BCSC, breast cancer surveillance consortium; BMI, body mass index; BOADICEA, breast and ovarian analysis of disease incidence and carrier estimation algorithm; FHx, family history; MHT, menopausal hormone therapy; NA, not applicable; LCIS, lobular carcinoma in situ; SNPs, single nucleotide polymorphisms

* eg mantle radiation for Hodgkins disease

**newest version of BOADICEA, V5, includes SNPs.

***includes family history of breast, ovarian, pancreatic and prostate cancer in 1st, 2 nd and 3rd degree relatives

Table 2: UK and US breast cancer prevention guidelines for women at increased risk

\begin{tabular}{|c|c|c|c|c|}
\hline & RRBM & RRSO & Medication \# & Lifestyle Factors \\
\hline $\begin{array}{l}\text { NCCN } \\
193\end{array}$ & $\begin{array}{l}\text { Consider for: } \\
\text { - high risk } \\
\text { BC gene } \\
\text { mutation } \\
\text { - compelling } \\
\text { FHx } \\
\text { - prior } \\
\text { thoracic } \\
\text { RT below } \\
\text { the age of } \\
30\end{array}$ & $\begin{array}{l}\text { Controversy } \\
\text { over whether } \\
\text { RRSO } \\
\text { reduces BC } \\
\text { risk for } \\
\text { BRCA } \\
\text { mutation } \\
\text { carriers but, } \\
\text { based on OC } \\
\text { risk, } \\
\text { recommend } \\
\text { for: } \\
\text { - BRCA1- } \\
\text { between } \\
\text { 35-40yrs } \\
\text { - BRCA2 - } \\
\text { between } \\
40-45 \\
\text { years } \\
\text { Exercise } \\
\text { caution in } \\
\text { prescribin } \\
\text { g HRT } \\
\text { post } \\
\text { RRSO }\end{array}$ & $\begin{array}{l}\text { Offer if } \\
\text { - } \geq 35 \text { years } \\
\text { old with } 5 \\
\text { year BC risk } \\
\geq 1.7 \% \\
\text { - have LCIS } \\
\text { Premenopausal: } \\
\text { Tamoxifen } \\
\text { Postmenopausal: } \\
\text { Tamoxifen, } \\
\text { raloxifene, } \\
\text { exemestane or } \\
\text { anastrozole }\end{array}$ & $\begin{array}{l}\text { - } \text { MHT (consider associated } \\
\text { BC risk) } \\
\text { - Alcohol (limit consumption) } \\
\text { - Exercise (premenopausal: } \\
\text { vigorous; postmenopausal: } \\
\text { moderate to vigorous) } \\
\text { - Healthy } \\
\text { - } \text { Beight } \\
\text { - Breastfeeding }\end{array}$ \\
\hline$\underset{194}{\mathrm{NICE}}$ & $\begin{array}{l}\text { Consider for: } \\
\text { - } \quad \text { lifetime } \\
\text { risk } \geq 30 \%\end{array}$ & $\begin{array}{l}\text { Consider for: } \\
\text { - } \quad \text { lifetime } \\
\text { risk } \geq 30 \% \\
\text { - offer MHT } \\
\text { up until }\end{array}$ & $\begin{array}{l}\text { Consider if: } \\
\text { - lifetime risk } \\
\quad \geq 17 \% \\
\text { Premenopausal: }\end{array}$ & $\begin{array}{l}\text { OCP- (if }>35 \text { years old } \\
\text { inform of increased risk of } \\
\text { BC. For BRCA } 1 \text { mutation } \\
\text { carriers discuss potential } \\
\text { increased risk of BC before }\end{array}$ \\
\hline
\end{tabular}




\begin{tabular}{|c|c|c|c|c|}
\hline & & $\begin{array}{l}\text { age of } \\
\text { natural } \\
\text { menopaus } \\
\text { e- } \\
\text { oestrogen } \\
\text { alone if } \\
\text { prior } \\
\text { hysterecto } \\
\text { my, } \\
\text { combined } \\
\text { MHT } \\
\text { otherwise }\end{array}$ & $\begin{array}{l}\text { Tamoxifen } \\
\text { Postmenopausal: } \\
\text { Anastrozole } \\
\text { (unless severe } \\
\text { osteoporosis) or } \\
\text { tamoxifen (if } \\
\text { severe } \\
\text { osteoporosis or } \\
\text { if the individual } \\
\text { does not want to } \\
\text { take } \\
\text { anastrozole) or } \\
\text { raloxifene (if } \\
\text { the individual } \\
\text { does not want to } \\
\text { take tamoxifen) }\end{array}$ & $\begin{array}{l}\text { age 40) } \\
\text { - Breastfeeding } \\
\text { - MHT (advise of increased } \\
\text { BC risk; tailor use to } \\
\text { individual circumstances; } \\
\text { use lowest dose for shortest } \\
\text { time possible (generally not } \\
\text { after age 50); prescribe } \\
\text { estrogen without } \\
\text { progesterone if } \\
\text { hysterectomy) } \\
\text { - Alcohol (advise of } \\
\text { increased BC risk) } \\
\text { - Smoking (advise cessation) } \\
\text { - Healthy weight } \\
\text { - Exercise }\end{array}$ \\
\hline$\underset{192}{\mathrm{ASCO}}$ & NA & NA & $\begin{array}{l}\text { Consider if: } \\
\geq 35 \text { years old } \\
\text { with } 5 \text { year risk } \\
\geq 1.66 \text { or have } \\
\text { LCIS } \\
\text { Premenopausal: } \\
\text { Tamoxifen } \\
\text { Postmenopausal: } \\
\text { Raloxifene, } \\
\text { exemestane or } \\
\text { anastrozole }\end{array}$ & NA \\
\hline
\end{tabular}

ACSO, American society of clinical oncology; BC, breast cancer; FHx, family history; HRT, hormone replacement therapy; LCIS, lobular carcinoma in situ; MHT, menopausal hormone therapy; NA, not applicable; NCCN, (US) national comprehensive cancer network; NICE, (UK) national institute for health and care excellence; OC, ovarian cancer; OCP, oral contraceptive pill; RRBM, risk-reducing bilateral mastectomy; RRSO, risk-reducing bilateral salpingo-oophorectomy; RT, radiotherapy.

\# 5 year course; no guideline currently recommends a 3 year lower dose course as tested in DeCensi $2019^{228}$, although ASCO guidelines suggest women who stop tamoxifen after 3 years will likely still derive benefit and that for women with intraepithelial neoplasia the low 5mg per day dose of tamoxifen may be an alternative if there are concerns over adverse events with the higher dose. 
Table 3: Ongoing registered clinical trials of pharmacological interventions for breast cancer prevention

\begin{tabular}{|c|c|c|c|c|c|c|c|c|}
\hline $\begin{array}{l}\text { Clinical trial } \\
\text { identifier }\end{array}$ & $\begin{array}{l}\text { Short } \\
\text { study } \\
\text { name }\end{array}$ & $\begin{array}{l}\text { Spons } \\
\text { or }\end{array}$ & $\begin{array}{l}\text { Pha } \\
\text { se }\end{array}$ & $\begin{array}{l}\text { Intervent } \\
\text { ion }\end{array}$ & $\begin{array}{l}\text { Study } \\
\text { design }\end{array}$ & $\begin{array}{l}\text { Study } \\
\text { population }\end{array}$ & $\begin{array}{l}\text { Primary } \\
\text { outcome }\end{array}$ & $\begin{array}{l}\text { Secondary } \\
\text { outcomes }\end{array}$ \\
\hline \multicolumn{9}{|c|}{ ENDOCRINE AGENTS } \\
\hline $\begin{array}{l}\text { NCT0240877 } \\
0^{250}\end{array}$ & $\begin{array}{l}\text { BC- } \\
\text { APPS1 }\end{array}$ & $\begin{array}{l}\text { Manch } \\
\text { ester } \\
\text { Univer } \\
\text { sity }\end{array}$ & II & $\begin{array}{ll}\text { - Ulipri } \\
\text { stal } \\
\text { aceta } \\
\text { te } \\
5 \mathrm{mg} \\
\text { oral } \\
\text { daily } \\
\text { for } 3 \\
\text { mont } \\
\text { hs }\end{array}$ & $\begin{array}{l}\text { Single } \\
\text { arm }\end{array}$ & $\begin{array}{ll}- & \text { Preme } \\
\text { nopaus } \\
\text { al } \\
\text { - } & >17 \% \\
& \text { lifetime } \\
\text { BC risk }\end{array}$ & $\begin{array}{l}\text { Change } \\
\text { in Ki67 } \\
\text { staining } \\
\text { of breast } \\
\text { epitheliu } \\
\text { m }\end{array}$ & $\begin{array}{ll}- & \% \\
\text { luminal, } \\
\text { basal } \\
\text { and } \\
\text { mixed } \\
\text { colonies } \\
\text { MRI } \\
\text { backgrou } \\
\text { nd } \\
\text { parenchy } \\
\text { ma } \\
\text { enhance } \\
\text { ment } \\
\text { side- } \\
\text { effects }\end{array}$ \\
\hline $\begin{array}{l}\text { NCT0007883 } \\
2^{262}\end{array}$ & IBIS-II & $\begin{array}{l}\text { Queen } \\
\text { Mary } \\
\text { Univer } \\
\text { sity of } \\
\text { Londo } \\
\mathrm{n}\end{array}$ & III & $\begin{array}{ll}\text { - Anas } & \text { trozo } \\
\text { le } \\
1 \mathrm{mg} \\
\text { oral } \\
\text { daily } \\
\text { for } 5 \\
\text { years } \\
\text { - } & \text { Place } \\
\text { bo }\end{array}$ & $\begin{array}{l}\text { Rando } \\
\text { mized, } \\
\text { double- } \\
\text { blind, } \\
\text { placeb } \\
\text { o- } \\
\text { control } \\
\text { led }\end{array}$ & $\begin{array}{ll}\text { - } & \text { Postme } \\
& \text { nopaus } \\
& \text { al } \\
- & 40-70 \\
& \text { years } \\
\text { old } \\
-\quad & \text { Increas } \\
\text { ed risk } \\
\text { of BC }\end{array}$ & $\begin{array}{l}\mathrm{BC} \\
\text { incidenc } \\
\mathrm{e} \\
\text { (invasiv } \\
\mathrm{e} \text { and } \\
\text { non- } \\
\text { invasive } \\
\text { ) }\end{array}$ & BC mortality \\
\hline $\begin{array}{l}\text { NCT0306361 } \\
9^{263}\end{array}$ & $\begin{array}{l}\text { Afimoxife } \\
\text { ne in } \\
\text { reducing } \\
\text { the risk } \\
\text { of } \mathrm{BC} \text { in } \\
\text { women } \\
\text { with } \\
\text { mammogr } \\
\text { aphically } \\
\text { dense brea } \\
\text { sts }\end{array}$ & $\begin{array}{l}\text { M.D. } \\
\text { Anders } \\
\text { on } \\
\text { Cancer } \\
\text { Center }\end{array}$ & II & $\begin{array}{l}\begin{array}{l}\text { Afim } \\
\text { oxife }\end{array} \\
\text { ne } \\
\text { gel } \\
4 \mathrm{mg} \\
\text { topic } \\
\text { ally } \\
\text { to } \\
\text { each } \\
\text { breas } \\
\mathrm{t} \\
\text { daily } \\
\text { for } \\
\text { up to } \\
52 \\
\text { week } \\
\mathrm{s} \\
\text { Place } \\
\text { bo }\end{array}$ & $\begin{array}{l}\text { Rando } \\
\text { mized, } \\
\text { Double } \\
\text {-Blind, } \\
\text { Placeb } \\
\text { o- } \\
\text { Control } \\
\text { led }\end{array}$ & $\begin{array}{l}\text { - } 40-69 \\
\text { years } \\
\text { old, or } \\
\text { less } \\
\text { than } 40 \\
\text { years if } \\
5 \text {-year } \\
\text { BCRAT } \\
\text { risk is } \geq \\
1.66 \% \\
\text { BIRADS } \\
\text { score } 3 \\
\text { or } 4\end{array}$ & $\begin{array}{l}\text { Percenta } \\
\text { ge } \\
\text { change } \\
\text { in } \\
\text { mammo } \\
\text { graphic } \\
\text { density } \\
\text { (using } \\
\text { Cumulus } \\
\text { software } \\
\text { ) }\end{array}$ & $\begin{array}{ll}\text { - } & \text { Other } \\
\text { breast } \\
\text { density } \\
\text { measure } \\
\text { s and } \\
\text { measure } \\
\text { ment } \\
\text { methods } \\
\text { Breast } \\
\text { tissue } \\
\text { biomark } \\
\text { ers } \\
\text { Hormone } \\
- \\
\text { mediate } \\
\text { d cellular } \\
\text { activity } \\
\text { Inflamm } \\
\text { atory } \\
\text { response } \\
\text { Markers }\end{array}$ \\
\hline
\end{tabular}




\begin{tabular}{|c|c|c|c|c|c|c|c|c|}
\hline & & & & & & & & $\begin{array}{ll}\text { of } \\
\text { tamoxife } \\
\mathrm{n} \\
\text { exposure } \\
\text { - } & \text { Toxicity } \\
\text { - } & \text { Pharmac } \\
\text { ogenomi } \\
\text { cs }\end{array}$ \\
\hline $\begin{array}{l}\text { EudraCT } \\
\text { Number } \\
2016-001087- \\
11^{264}\end{array}$ & CIBRAC & $\begin{array}{l}\text { Belfast } \\
\text { Health } \\
\text { and } \\
\text { Social } \\
\text { Care } \\
\text { Trust }\end{array}$ & N/A & $\begin{array}{ll}\text { - } & \begin{array}{l}\text { Tam } \\
\text { oxife }\end{array} \\
\mathbf{n} \\
20 \mathrm{mg} \\
\text { oral } \\
\text { daily } \\
\text { - Anas } \\
\text { trazo } \\
\text { le } \\
1 \mathrm{mg} \\
\text { oral } \\
\text { daily } \\
\text { with } \\
\text { Gose } \\
\text { relin } \\
3.6 \mathrm{~m} \\
\text { g s/c } \\
\text { every } \\
28 \\
\text { days }\end{array}$ & $\begin{array}{l}\text { Rando } \\
\text { mised, } \\
\text { open } \\
\text { label, } \\
\text { crossov } \\
\text { er }\end{array}$ & 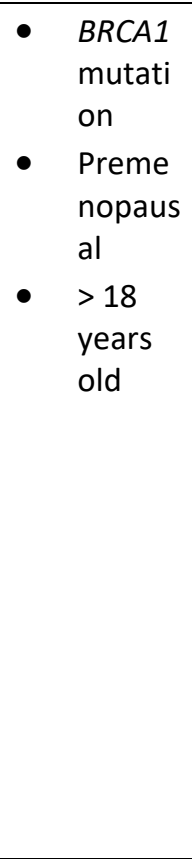 & $\begin{array}{l}\text { Feasibili } \\
\text { ty - } \\
\text { recruitm } \\
\text { ent and } \\
\text { complia } \\
\text { nce }\end{array}$ & $\begin{array}{l}\text { Tolerability - } \\
\text { QOL, AEs }\end{array}$ \\
\hline \multicolumn{9}{|c|}{ RETINOIDS } \\
\hline $\begin{array}{l}\text { NCT0332365 } \\
8^{263}\end{array}$ & $\begin{array}{l}\text { Bexaroten } \\
\text { e in } \\
\text { preventing } \\
\text { BC in } \\
\text { patients at } \\
\text { high risk } \\
\text { for BC }\end{array}$ & NCI & I & $\begin{array}{l}\text { Bexarote } \\
\text { ne } \\
\text { topically } \\
\text { to one } \\
\text { breast }\end{array}$ & $\begin{array}{l}\text { Single } \\
\text { arm, } \\
\text { dose } \\
\text { escalati } \\
\text { on }\end{array}$ & 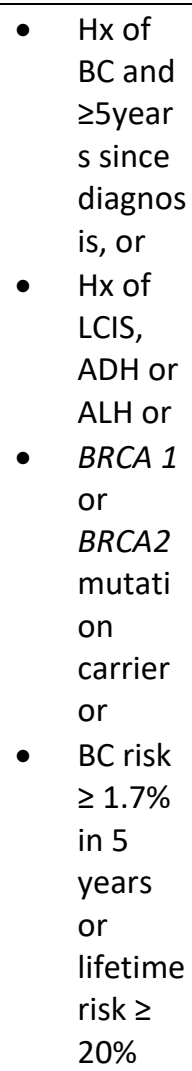 & $\begin{array}{l}\text { Incidenc } \\
e \text { of AEs }\end{array}$ & $\begin{array}{ll}\text { - } & \text { Systemic } \\
\text { toxicity } \\
\text { - } & \text { Bexarote } \\
\text { ne } \\
\text { concentr } \\
\text { ation } \\
\text { - Tissue } \\
\text { markers }\end{array}$ \\
\hline
\end{tabular}




\begin{tabular}{|c|c|c|c|c|c|c|c|c|}
\hline & & & & & & $\begin{array}{ll}-\quad \geq 18 \\
\text { years } \\
\text { old }\end{array}$ & & \\
\hline $\begin{array}{l}\text { EudraCT } \\
\text { Number } \\
2009-010260- \\
41^{241}\end{array}$ & $\begin{array}{l}\text { BC } \\
\text { prevention } \\
\text { with } \\
\text { fenretinid } \\
\text { e in young } \\
\text { women at } \\
\text { genetic } \\
\text { and } \\
\text { familial } \\
\text { risk. }\end{array}$ & $\begin{array}{l}\text { Istitut } \\
\text { o } \\
\text { Europ } \\
\text { eo Di } \\
\text { Oncolo } \\
\text { gia }\end{array}$ & III & 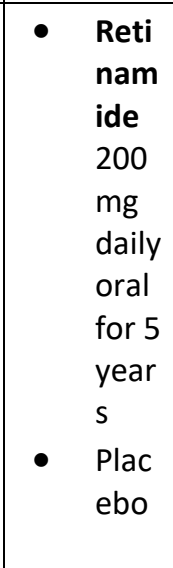 & $\begin{array}{l}\text { Double } \\
\text { blind, } \\
\text { random } \\
\text { ised, } \\
\text { placeb } \\
\text { o- } \\
\text { control } \\
\text { led }\end{array}$ & 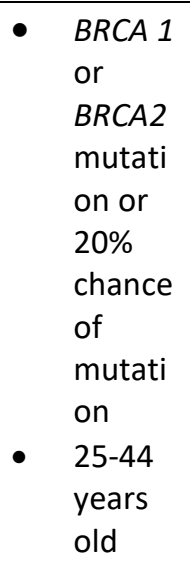 & $\begin{array}{l}\text { BC } \\
\text { incidenc } \\
\text { e } \\
\text { (invasiv } \\
\text { e and } \\
\text { DCIS) }\end{array}$ & $\begin{array}{l}\text { Incidence of } \\
\text { LCIS, atypical } \\
\text { hyperplasia, } \\
\text { ovarian } \\
\text { cancer and } \\
\text { other cancers }\end{array}$ \\
\hline \multicolumn{9}{|c|}{ BISPHOSPHONATES } \\
\hline $\begin{array}{l}\text { NCT0278180 } \\
5^{265}\end{array}$ & $\begin{array}{l}\text { Pilot study } \\
\text { of } \\
\text { bisphosph } \\
\text { onates } \\
\text { for BC }\end{array}$ & $\begin{array}{l}\text { Univer } \\
\text { sity of } \\
\text { Wisco } \\
\text { nsin }\end{array}$ & $\mathrm{I}$ & $\begin{array}{l}\text { Alendron } \\
\text { ate } \\
10 \mathrm{mg} \\
\text { daily for } \\
1-3 \text { weeks } \\
\text { before } \\
\text { breast } \\
\text { surgery }\end{array}$ & $\begin{array}{l}\text { Single } \\
\text { arm, } \\
\text { windo } \\
\text { w } \\
\text { study }\end{array}$ & $\begin{array}{ll}\text { - } & \text { Wome } \\
\mathrm{n} \geq 18 \\
\text { years } \\
\text { old } \\
\text { - } \quad \text { Referre } \\
\mathrm{d} \text { for } \\
\text { risk } \\
\text { reducin } \\
\text { g } \\
\text { mastec } \\
\text { tomy } \\
\text { Preme } \\
\text { nopaus } \\
\text { al }\end{array}$ & $\begin{array}{l}\text { Percenta } \\
\text { ge } \\
\text { change } \\
\text { in } \gamma \delta T \\
\text { cells in } \\
\text { breast } \\
\text { tissue }\end{array}$ & $\begin{array}{l}\text { - } \% \\
\text { change } \\
\text { in } \\
\text { mammar } \\
\text { y } \\
\text { epithelial } \\
\text { basal } \\
\text { cells } \\
\text { \% } \\
\text { change } \\
\text { in } \\
\text { mammar } \\
\text { y luminal } \\
\text { cells }\end{array}$ \\
\hline \multicolumn{9}{|c|}{ RANKL INHIBITORS } \\
\hline $\begin{array}{l}\text { ACTRN12614 } \\
000694617 \\
266\end{array}$ & BRCA-D & $\begin{array}{l}\text { Melbo } \\
\text { urne } \\
\text { Health }\end{array}$ & $\begin{array}{l}\mathrm{N} / \\
\mathrm{A}\end{array}$ & $\begin{array}{l}\text { Denosuma } \\
\text { b } 120 \mathrm{mg} \\
\text { s/c } \\
\text { monthly } \\
\text { for } 3 \\
\text { months }\end{array}$ & $\begin{array}{l}\text { Single } \\
\text { arm, } \\
\text { windo } \\
\text { w } \\
\text { study }\end{array}$ & $\begin{array}{ll}\text { - } B R C A 1 \\
\text { or } \\
\text { BRCA2 } \\
\text { mutati } \\
\text { on } \\
\text { carrier } \\
\text { - Preme } \\
\text { nopaus } \\
\text { al } \\
\text { 18-50 } \\
\text { years } \\
\text { old }\end{array}$ & $\begin{array}{l}\text { Change } \\
\text { in Ki67 } \\
\text { expressi } \\
\text { on in } \\
\text { breast } \\
\text { epitheliu } \\
\text { m }\end{array}$ & 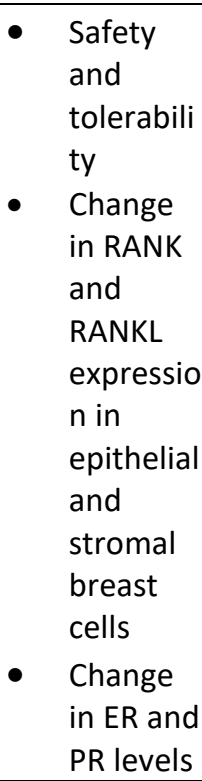 \\
\hline
\end{tabular}




\begin{tabular}{|c|c|c|c|c|c|c|c|c|}
\hline & & & & & & & & $\begin{array}{ll}\text { - } & \text { Change } \\
\text { in c-KIT, } \\
\text { ALDH1 } \\
\text { and } \\
\text { RANK } \\
\text { immunos } \\
\text { taining } \\
\text { - Change } \\
\text { in } \\
\text { luminal } \\
\text { cell } \\
\text { expressi } \\
\text { on } \\
\text { Change } \\
\text { in MRI } \\
\text { breast } \\
\text { parench } \\
\text { ymal } \\
\text { enhance } \\
\text { ment }\end{array}$ \\
\hline $\begin{array}{l}\text { EudraCT } \\
\text { Number } \\
2017-002505- \\
35^{248}\end{array}$ & BRCA-P & $A B C S G$ & III & $\begin{array}{l}\text { Denos } \\
\text { umab } \\
70 \mathrm{mg}, \\
\text { s/c } 6 \\
\text { month } \\
\text { ly for } \\
5 \\
\text { years } \\
\text { - Placeb } \\
\text { o }\end{array}$ & $\begin{array}{l}\text { Double } \\
\text { - blind, } \\
\text { random } \\
\text { ised, } \\
\text { placeb } \\
\text { o- } \\
\text { control } \\
\text { led }\end{array}$ & $\begin{array}{ll}\text { - } & \text { BRCA1 } \\
\text { mutati } \\
\text { on } \\
\text { - } & \text { Age } \geq \\
& 25 \\
\text { years } \\
\text { and } \leq \\
55 \\
\text { years }\end{array}$ & $\begin{array}{l}\text { BC } \\
\text { incidenc } \\
\text { e } \\
\text { (invasiv } \\
\text { e or } \\
\text { DCIS) }\end{array}$ & 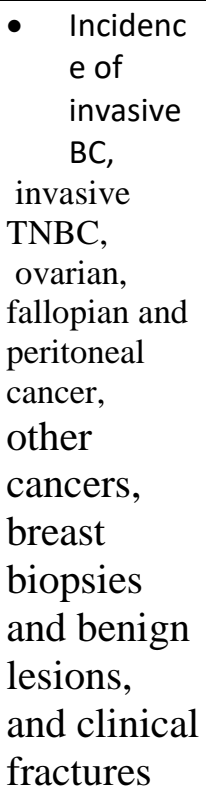 \\
\hline \multicolumn{9}{|c|}{ METFORMIN } \\
\hline $\begin{array}{l}\text { EudraCT } \\
\text { Number } \\
2009-009921- \\
28^{232}\end{array}$ & PLOTINA & $\begin{array}{l}\text { Istituti } \\
\text { Fisiote } \\
\text { rapici } \\
\text { Ospital } \\
\text { ieri }\end{array}$ & III & 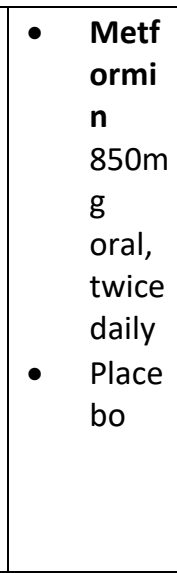 & $\begin{array}{l}\text { Double } \\
\text {-blind, } \\
\text { random } \\
\text { ized, } \\
\text { placeb } \\
\text { o } \\
\text { control } \\
\text { led }\end{array}$ & $\begin{array}{ll}- & \text { Postme } \\
& \text { nopaus } \\
& \text { al } \\
\text { - } & \text { Central } \\
& \text { obesity } \\
\text { - } & \text { Anothe } \\
& \text { r } \\
\text { compo } \\
\text { nent of } \\
\text { metab } \\
\text { olic } \\
\text { syndro } \\
\text { me }\end{array}$ & $\begin{array}{l}\mathrm{BC} \\
\text { incidenc } \\
\mathrm{e}\end{array}$ & $\begin{array}{l}\text { CVD } \\
\text { incidence }\end{array}$ \\
\hline
\end{tabular}


ABCSG = Austrian Breast \& Colorectal Cancer Study Group; ADH, atypical ductal hyperplasia; ALDH1, aldehyde dehydrogenase $1 ; A E$, adverse events; $A L H$, atypical lobular hyperplasia; BC, breast cancer; BCRAT, breast cancer risk assessment tool; BIRADS, breast imaging reporting and data system; CVD, cardiovascular disease; DCIS, ductal carcinoma in situ; ER, estrogen receptor; FHx, family history; LCIS, lobular carcinoma in situ; MRI, magnetic resonance imaging; $\mathrm{NCl}$, national cancer institute; N/A, not applicable; PR, progesterone receptor; $\mathrm{QOL}$, quality of life; RANK, receptor activator of nuclear factor-KB; RANKL, RANK ligand; s/c, subcutaneous; TNBC, triple negative breast cancer.

\section{Figure legends}

Figure 1:| Breast cancer risk modifiers and population frequency. The population frequency (horizontal x-axis) of genetic and non-genetic breast cancer risk modifiers are shown with their effects on, or associations with, relative risk of breast cancer (vertical y-axis). Rare, high risk alleles are shown as are rare, moderate risk alleles considered to have sufficient evidence to support their association. Examples of common low penetrance variants, of which there are now several hundred, are also listed ${ }^{18,19,21-23}$. For menopausal hormone therapy (MHT) and oral contraceptive pill (OCP) use, combined estrogen and progestogen therapy is assumed and dark blue denotes risk for current, long term users, mid blue denotes shorter periods of use and light blue past users ${ }^{33,267,268}$. $*$ refers only to postmenopausal obesity ${ }^{269}$. \# refers to 2 glasses of alcohol per day, which is the average consumption level in the $72 \%$ of the high socio-demographic index population who are drinkers ${ }^{134,144}$. Exercise refers to most active compared to least physically active ${ }^{124}$. The relative risk reduction associated with breastfeeding is for 12 months of cumulative breastfeeding ${ }^{31}$. Parity refers to a first full term childbirth prior to 25 years of age $\mathrm{e}^{35}$. The RR of breast cancer in women with moderate to high mammographic density ( $>25 \%$ to $>75 \%$ density) is 1.8 to 6.0 compared to women with low mammographic density ${ }^{104}$. Currently $50 \%$ of the female population are considered to have moderate $(25-50 \%)$ to high $(>75 \%)$ breast density ${ }^{107}$. Yellow refers to genetic risk factors, blue to reproductive and orange to lifestyle. APOBEC3, apolipoprotein B mRNA editing enzyme catalytic polypeptidelike; $A T M$, ataxia telangiectasia mutated; cadherin-1 ( $C D H 1$; which encodes E-cadherin), CASP8, caspase 8; CHEK2, checkpoint kinase 2; FGFR2, fibroblast growth factor receptor 2; $N B N$, nibrin; PALB2, partner and localizer of BRCA2; STK11, serine/threonine protein kinase 11. 
Figure 2The biological differences between high and low mammographic density.

Breast tissue with high mammographic density (HMD) has been shown to have increased levels of stroma and epithelium compared with areas with low mammographic density (LMD) ${ }^{108}$. Note that within the epithelium however, an increase in stem or progenitor cells has not yet been shown. Tissue with HMD also has an increased amount of structured collagen. BCs are often localized in areas of dense collagen or are stimulated to grow when the breast has increased stromal collagen ${ }^{270}$. Additionally, the collagen-binding proteoglycans, lumican, decorin, fibromodulin, and biglycan are also associated with $\mathrm{HMD}^{271}$. Lumican can induce initiation and progression of BC by increasing angiogenesis, epithelial cell growth, migration, and invasion ${ }^{272}$. The increased stiffness resulting from these extracellular matrix (ECM) changes may drive cancer formation through higher mechanical force and resistance to contractility on the epithelial cells (via focal adhesions and the RHO GTPase signalling pathway) driving proliferation ${ }^{273}$. Stromal fibroblasts in areas of HMD have also been shown to exhibit gene expression signatures associated with cancer stimulating pathways such as stress response, inflammation, stemness, and signal transduction ${ }^{274}$. BCs with immune infiltration are known to have better prognosis and may respond to chemotherapeutics and be responsive to immune based therapies ${ }^{275,276}$. However, less is known about immune infiltration in the normal breast and early, pre-invasive lesions. Tissue with HMD has been shown to have a pro-tumorigenic immune microenvironment including increased innate (macrophages and dendritic cells), adaptive ( $\mathrm{T}$ and $\mathrm{B}$ cells) and increased interleukin 6 (IL-6), which may aid escape from immune regulation for early tumor cell variants ${ }^{109}$. Furthermore, the ECM has been shown to modulate activation, fate determination, and chemotaxis of immune cells ${ }^{277-279}$ indicating that the changes may be interrelated.

Figure 3: Developing novel preventatives based on a deeper understanding of the early events in breast cancer development. Schematic of the normal breast, pre-neoplastic changes and invasive breast cancer $(\mathrm{BC})$ showing the alterations that occur and the drugs currently used in prevention and treatment. One of the earliest stages of cancer development is the transformation of a single cell within the epithelial layer. In the normal breast, the oncogene expressing cells are ejected from the epithelium by surrounding normal cells in a process called oncogenic extrusion ${ }^{280}$. Work is 
undergoing to assess oncogenic extrusion in early tumour development and the factors that control it. The selective estrogen receptor modulator (SERM), tamoxifen is used to prevent BC in women with normal breast tissue and also in those women at high risk of $\mathrm{BC}$ owing to pathogenic mutations. Recently, denosumab, a receptor activator of nuclear factor- $\kappa \mathrm{B}$ ligand (RANKL) inhibitor has shown promising results in $\mathrm{BC}$ prevention in $B R C A 1$ mutation carriers by targeting the $\mathrm{RANK}^{+}$luminal progenitor population that is increased in these women. Future work should determine whether $B R C A 2$ mutation status also alters the breast epithelial hierarchy and how this can be exploited to develop therapies for $B R C A 2$ mutation carriers. In terms of the non-genetic risk factors it is important that we define how body mass index (BMI), age and reproductive factors alter the breast epithelial cells. The epithelial cells sit embedded in a stromal and immune microenvironment, which is emerging as having a significant role in the growth and progression of pre-invasive and invasive $\mathrm{BC}$ ${ }^{258,260}$. In the stroma of pre-neoplastic lesions fibroblasts become activated and the macrophage and T cell populations are altered. Currently immune modulating therapies are not used this early in tumour development but as we define how the immune system changes at this time, it is possible they can also be used to prevent or delay tumour formation. In invasive BC, the luminal epithelial cells have transformed, extrusion does not occur and the basement membrane is breached. The epithelial cells can be targeted in invasive $\mathrm{BC}$ with, tamoxifen (for estrogen receptor $(\mathrm{ER})^{+} \mathrm{BCs}$ ) and trastuzumab (for human epidermal growth factor receptor $\left.2(\mathrm{HER} 2)^{+} \mathrm{BCs}\right)$. There are also additional changes to the stromal fibroblasts and immune cells (for example, fewer T cells and repolarisation of macrophages), which can further stimulate cancer growth. Immune-based therapies, such as pembrolizumab, the programmed cell death protein 1 (PD1) inhibitor, inhibitors of granulocyte colony-stimulating factor receptor (GCSFR) and colony stimulating factor 1 receptor (CSF1R) are currently being explored in cancer treatment. Similarly, cancer associated fibroblast (CAF)-targeting therapies, such as fibroblast activation protein (FAP) antibodies conjugated to cytotoxic drugs (FAP5-DM1) are being investigated. As we begin to understand more about the changes occurring in the pre-neoplastic breast, it can be envisioned that the use of additional epithelial and stromal or immune-targeted therapies will be explored also at this early timepoint. 


\section{The role of exogenous hormones in breast cancer risk}

A major change in reproductive behaviours in the last century has been the introduction and widespread use of exogenous estrogens in the form of hormonal contraceptives and menopausal hormone therapy (MHT), ${ }^{33,267,281-283}$ which increase ER positive breast cancer (BC) risk ${ }^{33,268,282-284}$. The oral contraceptive pill (OCP) is now the most popular form of contraception with a quarter of women of childbearing age in high income countries using it at any one time $e^{285}$.

In the late 1990s, a meta-analysis of individual data from over 150,000 women demonstrated that current users of OCPs had a $24 \%$ increased relative risk (RR) of BC. The increased risk attenuates after cessation and is no longer evident 10 years post-cessation ${ }^{267}$. A more recent, large Danish study supports these findings and also showed an increased risk associated with use of progestogencontaining intrauterine devices ${ }^{268}$. For OCPs, the RR of BC is higher in current users who commenced use prior to 20 years of age, but because the baseline risk of $\mathrm{BC}$ at such a young age is very low, for any given duration of use, early commencement of $\mathrm{OCP}$ does not contribute to more $\mathrm{BC}$ being diagnosed in younger women than in those who start later in life $\mathrm{e}^{267}$. Duration of use also impacts on risk; 5 years of use is associated with at least a 5\% increased RR whilst 10 and 13 years is associated with a $12 \%$ and $18 \%$ increase, respectively ${ }^{267,268}$.

A key point is that the increase in absolute risk of $\mathrm{BC}$ associated with hormonal contraception is low when the underlying risk is low (e.g. in young women at average lifetime risk of the disease), but when the underlying risk is higher (e.g. older premenopausal women with a strong family history of the disease) the increase in absolute risk is likely to be of more importance. In fact, it has been estimated that $7 \%$ of $\mathrm{BC}$ burden for premenopausal women is owing to the use of hormonal contraceptives for 5 or more years ${ }^{136}$. US statistics indicate that as much as $10 \%$ of OCP users are older premenopausal women aged 40-49 ${ }^{286}$. Therefore, when estimating the risk-benefit ratio for an individual woman, her underlying $\mathrm{BC}$ risk at her current age is an important consideration. 
The Collaborative Group on Hormonal Factors in Breast Cancer recently published their individual participant meta-analysis of the worldwide epidemiological evidence related to MHT and BC risk ${ }^{33}$. They estimated that about 1 million of the approximately 20 million BCs diagnosed in Western countries since 1990 were due to MHT use ${ }^{33}$. Every MHT type, except vaginal estrogens increased $\mathrm{BC}$ risk (compared with non-users), which steadily rose with duration of use and were greater for oestrogen and progestogen preparations (combined MHT) than oestrogen only ones. Specifically, for combined MHT use (1-4 years), there was a 60\% increase in risk of BC (RR: 1.60), and for estrogen only MHT, a 17\% increase (RR: 1·17). Risk was greater for longer durations of use: for example, for 5-14 years of combined MHT use, the risk was more than doubled (RR: 2.08) and it was 33\% higher for estrogen-only MHT (RR: 1·33). Furthermore, the RRs during years 5-14 were much greater for ER positive tumours than for ER negative tumours. After ceasing MHT, some excess risk persisted for more than 10 years but its magnitude was dependent on the duration of previous use ${ }^{33}$. These findings are consistent with other large studies ${ }^{284,287-289}$, although the women's health initiative (WHI) randomised trial showed a protective effect of estrogen only $\mathrm{MHT}$ for $\mathrm{BC}$, resulting in ongoing controversy over the risks and benefits of estrogen only MHT 290 .

The relationship between estrogen and $\mathrm{BC}$ risk is complex and it is hoped that pre-clinical work assessing the effects of estrogen alone and estrogen - progestogen therapies on breast tissue may reveal how these therapies alter the breast to impact on cancer risk.

\section{Glossary}

ADIPOKINE: cell signalling protein secreted by adipose (fat) cells

Basal-like breast cancer: breast cancer subtype that is more prevalent in African-American women, and are characterised by high histological grade, high mitotic indices and lack of ER and PR abd HER2 protein overexpression.

BC RISK ESTIMATION MODELS: Tools that estimate a person's likelihood of developing breast cancer within a specific timeframe. 
BILATERAL SALPINGO-OOPHORECTOMY: A surgical procedure to remove both ovaries and fallopian tubes.

CALIBRATION: the ratio of the observed number of breast cancer cases to the expected number; values of 1 indicate optimal calibration

DISCRIMINATORY ACCURACY: the ability of a risk model to separate individuals who will get breast cancer from those who will not. A value of 1.0 represents perfect discrimination, a value of 0.5 means that the model performance is no better than chance alone, values of $0.6-0.7$ are considered good and 0.5-0.6 sufficient

GYNAECOMASTIA: excessive enlargement of the male breast. May be unilateral (one side) or bilateral (both)

HAZARDS RATIO (HR): a measure of how often a particular event happens in one group compared to another group, over time. A HR=1.0 means that there is no difference in survival between the two groups. A HR $>1.0$ or $<1.0$ means that survival was better in one of the groups.

HOMOLOGOUS RECOMBINATION: the exchange of nucleotide sequences between two similar or identical molecules of DNA. It is used by cells to accurately repair damage that occurs on both strands of DNA, such as double-strand breaks or interstrand DNA crosslinks.

KLINEFELTER SYNDROME: A genetic condition, affecting about 1 in every 550 men, in which a male is born with an extra copy of the $\mathrm{X}$ chromosome. This results in higher levels of female hormones. 
LUMINAL PROGENITORS: A type of luminal epithelial cell within the mammary epithelium that has both luminal differentiation markers and progenitor activity (colony forming and repopulating activity in vivo).

MAMMARY STEM CELLS (MASCS): Cells within the mammary gland that have the capacity to form a new mammary tree when transplanted into a cleared mammary fat pad. Reside within the basal/myoepithelial compartment and can be identified with CD24/EpCAM and either CD29 or CD49f.

Mammographic density: Mammographic density (MD) describes the extent of white or radio-opaque tissue (dense area) on a mammogram, and percent MD is used to represent this dense area as a proportion of the total tissue area of the breast on a mammogram.

MENARCHE: The time in a girl's life when her first menstrual bleeding or period begins.

MENOPAUSAL HORMONE THERAPY: sex hormones given to treat symptoms or prevent longterm morbidities associated with female menopause Also known as hormone replacement therapy (HRT)

ODDS RATIO (OR): a statistic that quantifies the strength of the association between an exposure and an outcome. An $\mathrm{OR}=1$ means the exposure does not affect odds of outcome, an $\mathrm{OR}>1$ means the exposure is associated with higher odds of outcome and that an $\mathrm{OR}<1$ means the exposure is associated with lower odds of outcome.

ORAL CONTRACEPTIVE PILL: (OCP). A birth control pill taken orally. Most contain estrogen and progesterone which when given at certain times in the mentrual cycle at defined doses can prevent the ovary from releasing the egg for fertilization. 
PARITY: The state of having borne offspring (liveborn or stillborn). Also used to indicate the number of pregnancies reaching viable gestational age (liveborn or stillborn - pregnancies resulting in multiple births, such as twins, count as 1)

POST-PARTUM INVOLUTION PROCESS: A cell-death-mediated process by which the lactating breast returns to the pre-pregnant state after weaning (or after childbirth if lactation is not initiated). It is characterized by robust tissue remodeling.

RELATIVE RISK (RR): a ratio of the probability of an event occurring in the group exposed to the modifier of interest versus the probability of the event occurring in the non-exposed group. A relative risk of 1.5 means people exposed to the risk modifier, on average have a 50\% higher risk than those not exposed.

ABSOLUTE RISK: The absolute risk of a disease is the risk of developing the disease over a time period, e.g. a person may have a 1 in 10 risk (i.e a 10\% risk) of a certain disease in their life. Absolute risk is one of the most understandable ways of communicating health risks to the general public.

BILATERAL MASTECTOMY: removal of as much breast tissue as possible to reduce breast cancer risk

TRANSDERMAL THERAPY: a route of drug administration wherein the drug is delivered across the skin, via patches or creams, for systemic distribution.

Polygenic disease: A genetic disorder that is caused by the combined action of more than one gene

\section{Author contributions}

K.L.B and K.A.P researched data for the article, made substantial contributions to discussions of the content and wrote the article. J.C. provided vital input to the article and insight in to preventatives that are currently being trialled. All authors reviewed and/or edited the manuscript before submission.

\section{Competing interests}


The authors wish to disclose that CRUK licences the IBIS (Tyrer-Cuzick) model for commercial use and J.C. receives some benefit. K.A.P has a patent, System and Process of Cancer Risk Estimation (Australian Innovation Patent) issued regarding iPrevent. K.L.B has no competing interests.

\section{Acknowledgements}

KLB is a Victorian Cancer Agency mid-career fellow and is also supported by the Peter MacCallum Research Foundation and Harold Homes Equity Trustees grant. KAP is an Australian National Breast Cancer Foundation Fellow.

\section{Related Links}

https://tools.bcsc-scc.org/BC5yearRisk/intro.htm https://projects.iq.harvard.edu/bayesmendel/bayesmendel-r-package https://ccge.medschl.cam.ac.uk/boadicea/ https://bcrisktool.cancer.gov/calculator.html http://www.ems-trials.org/riskevaluator/ https://dceg.cancer.gov/research/cancer-types/breast-cancer/confluence-project

\section{Table of contents summary}

This review presents the evidence for the role of risk factors in breast cancer incidence and their inclusion in risk estimation tools as a step towards precision prevention to specifically target those women at increased risk for appropriate risk-reducing interventions.

\section{References}

1 Global Burden of Disease Cancer, C. et al. Global, Regional, and National Cancer Incidence, Mortality, Years of Life Lost, Years Lived With Disability, and DisabilityAdjusted Life-Years for 29 Cancer Groups, 1990 to 2016: A Systematic Analysis for the Global Burden of Disease Study. JAMA Oncol 4, 1553-1568, doi:10.1001/jamaoncol.2018.2706 (2018).

2 Narod, S. A., Iqbal, J. \& Miller, A. B. Why have breast cancer mortality rates declined? . J Cancer Policy 5, 8-17 (2015). 

trends in breast cancer incidence and mortality 1973-1997. Int J Epidemiol 34, 405412, doi:10.1093/ije/dyh414 (2005).

4 Boffetta, P. \& Parkin, D. M. Cancer in developing countries. CA Cancer J Clin 44, 81-90, doi:10.3322/canjclin.44.2.81 (1994).

5 Glass, A. G. \& Hoover, R. N. Rising incidence of breast cancer: relationship to stage and receptor status. Journal of the National Cancer Institute 82, 693-696 (1990).

6 Li, C. I., Daling, J. R. \& Malone, K. E. Incidence of invasive breast cancer by hormone receptor status from 1992 to 1998. J Clin Oncol 21, 28-34, doi:10.1200/JCO.2003.03.088 (2003).

7 Parkin, D. M. \& Fernandez, L. M. Use of statistics to assess the global burden of breast cancer. Breast J 12 Suppl 1, S70-80, doi:10.1111/j.1075-122X.2006.00205.X (2006).

8 Ries, L. A. G., Melbert, D. \& Krapcho, M. SEER Cancer Sta-tistics Review, 19752004. (Bethesda (MD), 2006).

9 Bigaard, J., Stahlberg, C., Jensen, M. B., Ewertz, M. \& Kroman, N. Breast cancer incidence by estrogen receptor status in Denmark from 1996 to 2007. Breast cancer research and treatment 136, 559-564, doi:10.1007/s10549-012-2269-0 (2012).

10 Coughlin, S. S. Epidemiology of Breast Cancer in Women., Vol. 1152 (Springer, Cham, 2019).

11 He, C. et al. A large-scale candidate gene association study of age at menarche and age at natural menopause. Hum Genet 128, 515-527, doi:10.1007/s00439-010-0878-4 (2010).

12 Stolk, L. et al. Meta-analyses identify 13 loci associated with age at menopause and highlight DNA repair and immune pathways. Nat Genet 44, 260-268, doi:10.1038/ng.1051 (2012).

13 Stone, J. et al. The heritability of mammographically dense and nondense breast tissue. Cancer Epidemiol Biomarkers Prev 15, 612-617, doi:10.1158/1055-9965.EPI05-0127 (2006).

14 Broca, P. Taite des tumeurs. Vol. 13 (Libraire De La Faculte De Medecine 1866).

15 Miki, Y. et al. A strong candidate for the breast and ovarian cancer susceptibility gene BRCA1. Science 266, 66-71, doi:10.1126/science.7545954 (1994).

16 Wooster, R. et al. Identification of the breast cancer susceptibility gene BRCA2. Nature 378, 789-792, doi:10.1038/378789a0 (1995).

17 Ligtenberg, M. J. et al. Characteristics of small breast and/or ovarian cancer families with germline mutations in BRCA1 and BRCA2. Br J Cancer 79, 1475-1478, doi:10.1038/sj.bjc.6690235 (1999).

18 Kuchenbaecker, K. B. et al. Risks of Breast, Ovarian, and Contralateral Breast Cancer for BRCA1 and BRCA2 Mutation Carriers. JAMA 317, 2402-2416, doi:10.1001/jama.2017.7112 (2017).

19 Easton, D. F. et al. Gene-panel sequencing and the prediction of breast-cancer risk. $N$ Engl J Med 372, 2243-2257, doi:10.1056/NEJMsr1501341 (2015).

20 Network, N. C. C. Genetic/Familial high-risk assessment: breast and ovarian. (National Comprehensive Cancer Network, 2019).

21 Michailidou, K. et al. Genome-wide association analysis of more than 120,000 individuals identifies 15 new susceptibility loci for breast cancer. Nat Genet 47, 373380, doi:10.1038/ng.3242 (2015).

22 Mavaddat, N. et al. Prediction of breast cancer risk based on profiling with common genetic variants. Journal of the National Cancer Institute 107, doi:10.1093/jnci/djv036 (2015). 
23 Mavaddat, N. et al. Polygenic Risk Scores for Prediction of Breast Cancer and Breast Cancer Subtypes. Am J Hum Genet 104, 21-34, doi:10.1016/j.ajhg.2018.11.002 (2019).

24 Rudolph, A. et al. Joint associations of a polygenic risk score and environmental risk factors for breast cancer in the Breast Cancer Association Consortium. Int $J$ Epidemiol 47, 526-536, doi:10.1093/ije/dyx242 (2018).

25 Muranen, T. A. et al. Genetic modifiers of CHEK2*1100delC-associated breast cancer risk. Genet Med 19, 599-603, doi:10.1038/gim.2016.147 (2017).

26 Kuchenbaecker, K. B. et al. Associations of common breast cancer susceptibility alleles with risk of breast cancer subtypes in BRCA1 and BRCA2 mutation carriers. Breast cancer research : BCR 16, 3416, doi:10.1186/s13058-014-0492-9 (2014).

27 Esserman, L. J., Study, W. \& Athena, I. The WISDOM Study: breaking the deadlock in the breast cancer screening debate. NPJ Breast Cancer 3, 34, doi:10.1038/s41523017-0035-5 (2017).

28 Evans, D. G. R. et al. Breast cancer pathology and stage are better predicted by risk stratification models that include mammographic density and common genetic variants. Breast cancer research and treatment 176, 141-148, doi:10.1007/s10549019-05210-2 (2019).

29 Gabrielson, M. et al. Cohort Profile: The Karolinska Mammography Project for Risk Prediction of Breast Cancer (KARMA). Int J Epidemiol 46, 1740-1741g, doi:10.1093/ije/dyw357 (2017).

30 French, J. D. et al. Functional variants at the 11q13 risk locus for breast cancer regulate cyclin D1 expression through long-range enhancers. Am J Hum Genet 92 , 489-503, doi:10.1016/j.ajhg.2013.01.002 (2013).

31 Collaborative Group on Hormonal Factors in Breast, C. Breast cancer and breastfeeding: collaborative reanalysis of individual data from 47 epidemiological studies in 30 countries.... Lancet 360, 187-195 (2002).

32 Collaborative Group on Hormonal Factors in Breast, C. Menarche, menopause, and breast cancer risk: individual participant meta-analysis, including 118964 women with breast cancer from 117 epidemiological studies. The Lancet. Oncology 13, 11411151, doi:10.1016/S1470-2045(12)70425-4 (2012).

33 Collaborative Group on Hormonal Factors in Breast, C. Type and timing of menopausal hormone therapy and breast cancer risk: individual participant metaanalysis of the worldwide epidemiological evidence. Lancet, doi:10.1016/S01406736(19)31709-X (2019).

34 Dall, G. V. \& Britt, K. L. Estrogen Effects on the Mammary Gland in Early and Late Life and Breast Cancer Risk. Front Oncol 7, 110, doi:10.3389/fonc.2017.00110 (2017).

35 MacMahon, B. et al. Age at first birth and breast cancer risk. Bull World Health Organ 43, 209-221 (1970).

36 Morris, D. H., Jones, M. E., Schoemaker, M. J., Ashworth, A. \& Swerdlow, A. J. Secular trends in age at menarche in women in the UK born 1908-93: results from the Breakthrough Generations Study. Paediatr Perinat Epidemiol 25, 394-400, doi:10.1111/j.1365-3016.2011.01202.x (2011).

37 Braithwaite, D. et al. Socioeconomic status in relation to early menarche among black and white girls. Cancer Causes Control 20, 713-720, doi:10.1007/s10552-008-9284-9 (2009).

38 Sisti, J. S. et al. Reproductive risk factors in relation to molecular subtypes of breast cancer: Results from the nurses' health studies. Int J Cancer 138, 2346-2356, doi:10.1002/ijc.29968 (2016). 
39 Silva, C. A. et al. Gonadal function in adolescents and young women with juvenile systemic lupus erythematosus. Lupus 11, 419-425, doi:10.1191/0961203302lu219oa (2002).

40 Harris, M. A., Prior, J. C. \& Koehoorn, M. Age at menarche in the Canadian population: secular trends and relationship to adulthood BMI. J Adolesc Health 43, 548-554, doi:10.1016/j.jadohealth.2008.07.017 (2008).

41 Fernandez-Rhodes, L. et al. Association of adiposity genetic variants with menarche timing in 92,105 women of European descent. Am J Epidemiol 178, 451-460, doi:10.1093/aje/kws473 (2013).

42 Chisholm, J. S., Quinlivan, J. A., Petersen, R. W. \& Coall, D. A. Early stress predicts age at menarche and first birth, adult attachment, and expected lifespan. Hum Nat 16, 233-265, doi:10.1007/s12110-005-1009-0 (2005).

43 Carwile, J. L. et al. Sugar-sweetened beverage consumption and age at menarche in a prospective study of US girls. Hum Reprod 30, 675-683, doi:10.1093/humrep/deu349 (2015).

44 Belsky, J., Steinberg, L. \& Draper, P. Childhood experience, interpersonal development, and reproductive strategy: and evolutionary theory of socialization. Child Dev 62, 647-670 (1991).

45 Behie, A. M. \& O'Donnell, M. H. Prenatal smoking and age at menarche: influence of the prenatal environment on the timing of puberty. Hum Reprod 30, 957-962, doi:10.1093/humrep/dev033 (2015).

46 Elks, C. E. et al. Thirty new loci for age at menarche identified by a meta-analysis of genome-wide association studies. Nat Genet 42, 1077-1085, doi:10.1038/ng.714 (2010).

47 Boynton-Jarrett, R. et al. Gestational weight gain and daughter's age at menarche. $J$ Womens Health (Larchmt) 20, 1193-1200, doi:10.1089/jwh.2010.2517 (2011).

48 Deardorff, J. et al. Maternal pre-pregnancy BMI, gestational weight gain, and age at menarche in daughters. Matern Child Health J 17, 1391-1398, doi:10.1007/s10995012-1139-z (2013).

49 Gao, Y. T. et al. Association of menstrual and reproductive factors with breast cancer risk: results from the Shanghai Breast Cancer Study. Int J Cancer 87, 295-300, doi:10.1002/1097-0215(20000715)87:2<295::aid-ijc23>3.0.co;2-7 (2000).

50 O'Brien, K. M., Sun, J., Sandler, D. P., DeRoo, L. A. \& Weinberg, C. R. Risk factors for young-onset invasive and in situ breast cancer. Cancer Causes Control 26, 17711778, doi:10.1007/s10552-015-0670-9 (2015).

51 Reeves, G. K. et al. Reproductive factors and specific histological types of breast cancer: prospective study and meta-analysis. Br J Cancer 100, 538-544, doi:10.1038/sj.bjc.6604853 (2009).

52 Rodstrom, K. et al. Evidence for a secular trend in menopausal age: a population study of women in Gothenburg. Menopause 10, 538-543, doi:10.1097/01.GME.0000094395.59028.0F (2003).

53 Gold, E. B. et al. Factors related to age at natural menopause: longitudinal analyses from SWAN. Am J Epidemiol 178, 70-83, doi:10.1093/aje/kws421 (2013).

54 Gold, E. B. et al. Factors associated with age at natural menopause in a multiethnic sample of midlife women. Am J Epidemiol 153, 865-874, doi:10.1093/aje/153.9.865 (2001).

55 Gold, E. B. The timing of the age at which natural menopause occurs. Obstet Gynecol Clin North Am 38, 425-440, doi:10.1016/j.ogc.2011.05.002 (2011). 
56 He, L. N. et al. Association study of the oestrogen signalling pathway genes in relation to age at natural menopause. J Genet 86, 269-276, doi:10.1007/s12041-0070034-7 (2007).

57 Weel, A. E. et al. Estrogen receptor polymorphism predicts the onset of natural and surgical menopause. J Clin Endocrinol Metab 84, 3146-3150, doi:10.1210/jcem.84.9.5981 (1999).

58 den Tonkelaar, I., te Velde, E. R. \& Looman, C. W. Menstrual cycle length preceding menopause in relation to age at menopause. Maturitas 29, 115-123, doi:10.1016/s0378-5122(98)00013-9 (1998).

59 Ramazzini, B. De Morbis Artificum (Diseases of Workers). . (1940).

60 Albrektsen, G., Heuch, I., Hansen, S. \& Kvale, G. Breast cancer risk by age at birth, time since birth and time intervals between births: exploring interaction effects. $\mathrm{Br} J$ Cancer 92, 167-175, doi:10.1038/sj.bjc.6602302 (2005).

61 Ursin, G. et al. Reproductive factors and subtypes of breast cancer defined by hormone receptor and histology. Br J Cancer 93, 364-371, doi:10.1038/sj.bjc.6602712 (2005).

62 Ma, H., Bernstein, L., Pike, M. C. \& Ursin, G. Reproductive factors and breast cancer risk according to joint estrogen and progesterone receptor status: a meta-analysis of epidemiological studies. Breast cancer research : BCR 8, R43, doi:10.1186/bcr1525 (2006).

63 Anderson, K. N., Schwab, R. B. \& Martinez, M. E. Reproductive risk factors and breast cancer subtypes: a review of the literature. Breast cancer research and treatment 144, 1-10, doi:10.1007/s10549-014-2852-7 (2014).

64 Tamimi, R. M. et al. Traditional breast cancer risk factors in relation to molecular subtypes of breast cancer. Breast cancer research and treatment 131, 159-167, doi:10.1007/s10549-011-1702-0 (2012).

65 Gaudet, M. M. et al. Risk factors by molecular subtypes of breast cancer across a population-based study of women 56 years or younger. Breast cancer research and treatment 130, 587-597, doi:10.1007/s10549-011-1616-x (2011).

66 Hamilton, B. E., Martin, J. A., Osterman, M. J. K. \& Rossen, L. M. Births: Provisional data for 2018. . (2019).

67 Statistics, A. B. o. Births, Australia, 2017, Cat. No. 3301.0 (Australia, 2018).

68 Statistics, O. f. N. Births in England and Wales 2018, statistical bulletin. (England, 2019).

69 Livingstone, G. \& Cohn, D. Childlessness up among all women; down among women with advanced degrees. (Pew Research Center 2010).

70 welfare, A. I. o. H. a. Reproductive health indicators Australia 2002, Cat. no: PER 20. (Pew Research Center 2003).

71 Welfare, A. I. o. H. a. Cancer In Australia 2017, Cat. No. CAN 100. (Australian Institute of Health and Welfare Canberra, 2017).

72 Martin, J. A., Hamilton, B. E., Osterman, M. J. K., Driscoll, A. K. \& Drake, P. Final data for 2017. National Vital Statistics Reports; vol 67 no 8. . Report No. 1568-7856 (Electronic)

1568-7856 (Linking), 844-855 (Hyattsville, MD, 2018).

73 Huo, D. et al. Parity and breastfeeding are protective against breast cancer in Nigerian women. Br J Cancer 98, 992-996, doi:10.1038/sj.bjc.6604275 (2008).

74 Khalis, M. et al. Menstrual and reproductive factors and risk of breast cancer: A casecontrol study in the Fez region, Morocco. PloS one 13, e0191333, doi:10.1371/journal.pone.0191333 (2018). 
75 Schedin, P. Pregnancy-associated breast cancer and metastasis. Nat Rev Cancer 6, 281-291, doi:10.1038/nrc1839 (2006).

76 Britt, K., Ashworth, A. \& Smalley, M. Pregnancy and the risk of breast cancer. Endocr Relat Cancer 14, 907-933, doi:10.1677/ERC-07-0137 (2007).

77 Dall, G. V. et al. Estrogen receptor subtypes dictate the proliferative nature of the mammary gland. J Endocrinol 237, 323-336, doi:10.1530/JOE-17-0582 (2018).

78 Chang, C. C. et al. A human breast epithelial cell type with stem cell characteristics as target cells for carcinogenesis. Radiat Res 155, 201-207 (2001).

79 Russo, J., Tay, L. K. \& Russo, I. H. Differentiation of the mammary gland and susceptibility to carcinogenesis. Breast cancer research and treatment 2, 5-73 (1982).

80 Russo, I. H. \& Russo, J. Developmental stage of the rat mammary gland as determinant of its susceptibility to 7,12-dimethylbenz[a] anthracene. Journal of the National Cancer Institute 61, 1439-1449 (1978).

81 Land, C. E. et al. Incidence of female breast cancer among atomic bomb survivors, Hiroshima and Nagasaki, 1950-1990. Radiat Res 160, 707-717 (2003).

82 Tokunaga, M. et al. Incidence of female breast cancer among atomic bomb survivors, 1950-1985. Radiat Res 138, 209-223 (1994).

83 Britt, K. L. et al. Pregnancy in the mature adult mouse does not alter the proportion of mammary epithelial stem/progenitor cells. Breast cancer research : BCR 11, R20, doi:10.1186/bcr2245 (2009).

84 Meier-Abt, F. et al. Parity induces differentiation and reduces Wnt/Notch signaling ratio and proliferation potential of basal stem/progenitor cells isolated from mouse mammary epithelium. Breast cancer research : BCR 15, R36, doi:10.1186/bcr3419 (2013).

85 Siwko, S. K. et al. Evidence that an early pregnancy causes a persistent decrease in the number of functional mammary epithelial stem cells--implications for pregnancyinduced protection against breast cancer. Stem Cells 26, 3205-3209, doi:2008-0103 [pii]

10.1634/stemcells.2008-0103 (2008).

86 Dall, G. V. et al. SCA-1 Labels a Subset of Estrogen-Responsive Bipotential Repopulating Cells within the CD24+ CD49fhi Mammary Stem Cell-Enriched Compartment. Stem Cell Reports 8, 417-431, doi:10.1016/j.stemcr.2016.12.022 (2017).

87 Jindal, S. et al. Postpartum breast involution reveals regression of secretory lobules mediated by tissue-remodeling. Breast cancer research : BCR 16, R31, doi:10.1186/bcr3633 (2014).

88 Martinson, H. A., Jindal, S., Durand-Rougely, C., Borges, V. F. \& Schedin, P. Wound healing-like immune program facilitates postpartum mammary gland involution and tumor progression. Int J Cancer 136, 1803-1813, doi:10.1002/ijc.29181 (2015).

89 Santucci-Pereira, J. et al. Genomic signature of parity in the breast of premenopausal women. Breast cancer research : BCR 21, 46, doi:10.1186/s13058-019-1128-x (2019).

90 Balogh, G. A. et al. Genomic signature induced by pregnancy in the human breast. Int J Oncol 28, 399-410 (2006).

91 Lambertini, M. et al. Reproductive behaviors and risk of developing breast cancer according to tumor subtype: A systematic review and meta-analysis of epidemiological studies. Cancer Treat Rev 49, 65-76, doi:10.1016/j.ctrv.2016.07.006 (2016).

92 Hadjisavvas, A. et al. An investigation of breast cancer risk factors in Cyprus: a case control study. BMC Cancer 10, 447, doi:10.1186/1471-2407-10-447 (2010). 
93 Fortner, R. T. et al. Parity, breastfeeding, and breast cancer risk by hormone receptor status and molecular phenotype: results from the Nurses' Health Studies. Breast cancer research : BCR 21, 40, doi:10.1186/s13058-019-1119-y (2019).

94 Islami, F. et al. Breastfeeding and breast cancer risk by receptor status--a systematic review and meta-analysis. Ann Oncol 26, 2398-2407, doi:10.1093/annonc/mdv379 (2015).

95 Takabatake, Y. et al. Lactation opposes pappalysin-1-driven pregnancy-associated breast cancer. EMBO Mol Med 8, 388-406, doi:10.15252/emmm.201606273 (2016).

96 ORGANIZATION, W. H. Infant and young child nutrition (2002).

97 Welfare., A. I. o. H. a. Australian national infant feeding survey: indicator results. . (Canberra, 2010).

98 McAndrew, F., Thompson, J. \& Fellows, L. Infant feeding survey 2010. . (2012).

99 Ayton, J., van der Mei, I., Wills, K., Hansen, E. \& Nelson, M. Cumulative risks and cessation of exclusive breast feeding: Australian cross-sectional survey. Arch Dis Child 100, 863-868, doi:10.1136/archdischild-2014-307833 (2015).

100 Victora, C. G. et al. Breastfeeding in the 21st century: epidemiology, mechanisms, and lifelong effect. Lancet 387, 475-490, doi:10.1016/S0140-6736(15)01024-7 (2016).

101 Rollins, N. C. et al. Why invest, and what it will take to improve breastfeeding practices? Lancet 387, 491-504, doi:10.1016/S0140-6736(15)01044-2 (2016).

102 Sickles, E. A., D’Orsi, C.J., Bassett, L.W., . ACR BI-RADS Mammography. . Vol. 5th Edition 134-136 (2013).

103 Spak, D. A., Plaxco, J. S., Santiago, L., Dryden, M. J. \& Dogan, B. E. BI-RADS((R)) fifth edition: A summary of changes. Diagn Interv Imaging 98, 179-190, doi:10.1016/j.diii.2017.01.001 (2017).

104 McCormack, V. A. \& dos Santos Silva, I. Breast density and parenchymal patterns as markers of breast cancer risk: a meta-analysis. Cancer Epidemiol Biomarkers Prev 15, 1159-1169, doi:10.1158/1055-9965.EPI-06-0034 (2006).

105 Krishnan, K. et al. Mammographic density and risk of breast cancer by mode of detection and tumor size: a case-control study. Breast cancer research : BCR 18, 63, doi:10.1186/s13058-016-0722-4 (2016).

106 Hopper, J. L. Odds per adjusted standard deviation: comparing strengths of associations for risk factors measured on different scales and across diseases and populations. Am J Epidemiol 182, 863-867, doi:10.1093/aje/kwv193 (2015).

107 Sprague, B. L. et al. Prevalence of mammographically dense breasts in the United States. Journal of the National Cancer Institute 106, doi:10.1093/jnci/dju255 (2014).

108 Huo, C. W. et al. High mammographic density is associated with an increase in stromal collagen and immune cells within the mammary epithelium. Breast cancer research : BCR 17, 79, doi:10.1186/s13058-015-0592-1 (2015).

109 Huo, C. W. et al. High mammographic density in women is associated with protumor inflammation. Breast cancer research : BCR 20, 92, doi:10.1186/s13058-018-1010-2 (2018).

110 Cuzick, J. et al. Tamoxifen-induced reduction in mammographic density and breast cancer risk reduction: a nested case-control study. Journal of the National Cancer Institute 103, 744-752, doi:10.1093/jnci/djr079 (2011).

111 Shawky, M. S. et al. Mammographic density: a potential monitoring biomarker for adjuvant and preventative breast cancer endocrine therapies. Oncotarget 8, 55785591, doi:10.18632/oncotarget.13484 (2017). 
112 Wolfe, J. N. Risk for breast cancer development determined by mammographic parenchymal pattern. Cancer 37, 2486-2492, doi:10.1002/10970142(197605)37:5<2486::aid-cncr2820370542>3.0.co;2-8 (1976).

113 Boyd, N. F. et al. Quantitative classification of mammographic densities and breast cancer risk: results from the Canadian National Breast Screening Study. Journal of the National Cancer Institute 87, 670-675, doi:10.1093/jnci/87.9.670 (1995).

114 Suzuki, R., Orsini, N., Saji, S., Key, T. J. \& Wolk, A. Body weight and incidence of breast cancer defined by estrogen and progesterone receptor status--a meta-analysis. Int J Cancer 124, 698-712, doi:10.1002/ijc.23943 (2009).

115 Renehan, A. G., Zwahlen, M. \& Egger, M. Adiposity and cancer risk: new mechanistic insights from epidemiology. Nat Rev Cancer 15, 484-498, doi:10.1038/nrc3967 (2015).

116 Travis, R. C. \& Key, T. J. Oestrogen exposure and breast cancer risk. Breast cancer research : BCR 5, 239-247, doi:10.1186/bcr628 (2003).

117 Brinton, L. A. et al. Anthropometric and hormonal risk factors for male breast cancer: male breast cancer pooling project results. Journal of the National Cancer Institute 106, djt465, doi:10.1093/jnci/djt465 (2014).

118 Eliassen, A. H., Colditz, G. A., Rosner, B., Willett, W. C. \& Hankinson, S. E. Adult weight change and risk of postmenopausal breast cancer. JAMA 296, 193-201, doi:10.1001/jama.296.2.193 (2006).

119 Harvie, M. et al. Association of gain and loss of weight before and after menopause with risk of postmenopausal breast cancer in the Iowa women's health study. Cancer Epidemiol Biomarkers Prev 14, 656-661, doi:10.1158/1055-9965.EPI-04-0001 (2005).

120 Mannisto, S. et al. Body-size indicators and risk of breast cancer according to menopause and estrogen-receptor status. Int J Cancer 68, 8-13, doi:10.1002/(SICI)1097-0215(19960927)68:1<8::AID-IJC2>3.0.CO;2-V (1996).

121 Keum, N. et al. Adult weight gain and adiposity-related cancers: a dose-response meta-analysis of prospective observational studies. Journal of the National Cancer Institute 107, doi:10.1093/jnci/dju428 (2015).

122 Renehan, A. G. et al. Young adulthood body mass index, adult weight gain and breast cancer risk: the PROCAS Study (United Kingdom). Br J Cancer, doi:doi: 10.1038/s41416-020-0807-9 (2020).

123 Lynch, B. M., Neilson, H. K. \& Friedenreich, C. M. Physical activity and breast cancer prevention. Recent Results Cancer Res 186, 13-42, doi:10.1007/978-3-64204231-7_2 (2011).

124 Neilson, H. K. et al. Moderate-vigorous recreational physical activity and breast cancer risk, stratified by menopause status: a systematic review and meta-analysis. Menopause 24, 322-344, doi:10.1097/GME.0000000000000745 (2017).

125 Research., W. C. R. F. A. I. f. C. Continuous Update Project Expert Report 2018. Physical activity and the risk of cancer. . Report No. 0022-2623 (Print)

0022-2623 (Linking), (2018).

126 Wu, Y., Zhang, D. \& Kang, S. Physical activity and risk of breast cancer: a metaanalysis of prospective studies. Breast cancer research and treatment 137, 869-882, doi:10.1007/s10549-012-2396-7 (2013).

127 Research., W. C. R. F. A. I. f. C. Diet, nutrition, physical activity and breast cancer., (2018).

128 Lammert, J. et al. Physical activity during adolescence and young adulthood and the risk of breast cancer in BRCA1 and BRCA2 mutation carriers. Breast cancer research and treatment 169, 561-571, doi:10.1007/s10549-018-4694-1 (2018). 
129 Wang, M. et al. Prepubertal physical activity up-regulates estrogen receptor beta, BRCA1 and 553 mRNA expression in the rat mammary gland. Breast cancer research and treatment 115, 213-220, doi:10.1007/s10549-008-0062-x (2009).

130 Kurgan, N. et al. Inhibition of Human Lung Cancer Cell Proliferation and Survival by Post-Exercise Serum Is Associated with the Inhibition of Akt, mTOR, p70 S6K, and Erk1/2. Cancers (Basel) 9, doi:10.3390/cancers9050046 (2017).

131 Rundqvist, H. et al. Effect of acute exercise on prostate cancer cell growth. PloS one 8, e67579, doi:10.1371/journal.pone.0067579 (2013).

132 Dethlefsen, C. et al. Exercise-Induced Catecholamines Activate the Hippo Tumor Suppressor Pathway to Reduce Risks of Breast Cancer Development. Cancer Res 77, 4894-4904, doi:10.1158/0008-5472.CAN-16-3125 (2017).

133 National Statistics NHS. Health Survey for England 2012. (2013).

134 Chen, W. Y., Rosner, B., Hankinson, S. E., Colditz, G. A. \& Willett, W. C. Moderate alcohol consumption during adult life, drinking patterns, and breast cancer risk. JAMA 306, 1884-1890, doi:10.1001/jama.2011.1590 (2011).

135 Allen, N. E. et al. Moderate alcohol intake and cancer incidence in women. Journal of the National Cancer Institute 101, 296-305, doi:10.1093/jnci/djn514 (2009).

136 Arriaga, M. E. et al. The preventable burden of breast cancers for premenopausal and postmenopausal women in Australia: A pooled cohort study. Int J Cancer, doi:10.1002/ijc.32231 (2019).

137 Singletary, K. W. \& Gapstur, S. M. Alcohol and breast cancer: review of epidemiologic and experimental evidence and potential mechanisms. JAMA 286, 2143-2151, doi:10.1001/jama.286.17.2143 (2001).

138 Dorgan, J. F. et al. Serum hormones and the alcohol-breast cancer association in postmenopausal women. Journal of the National Cancer Institute 93, 710-715, doi:10.1093/jnci/93.9.710 (2001).

139 Triano, E. A. et al. Class I alcohol dehydrogenase is highly expressed in normal human mammary epithelium but not in invasive breast cancer: implications for breast carcinogenesis. Cancer Res 63, 3092-3100 (2003).

140 Seitz, H. K. \& Stickel, F. Acetaldehyde as an underestimated risk factor for cancer development: role of genetics in ethanol metabolism. Genes Nutr 5, 121-128, doi:10.1007/s12263-009-0154-1 (2010).

141 Meadows, G. G. \& Zhang, H. Effects of Alcohol on Tumor Growth, Metastasis, Immune Response, and Host Survival. Alcohol Res 37, 311-322 (2015).

142 Research., W. C. R. F. A. I. f. C. Food, Nutrition, Physical Activity, and the Prevention of Cancer: a Global Perspective. . (Washington, DC: , 2007).

143 Ronksley, P. E., Brien, S. E., Turner, B. J., Mukamal, K. J. \& Ghali, W. A. Association of alcohol consumption with selected cardiovascular disease outcomes: a systematic review and meta-analysis. BMJ 342, d671, doi:10.1136/bmj.d671 (2011).

144 Collaborators, G. B. D. A. Alcohol use and burden for 195 countries and territories, 1990-2016: a systematic analysis for the Global Burden of Disease Study 2016.

Lancet 392, 1015-1035, doi:10.1016/S0140-6736(18)31310-2 (2018).

145 Hopper, J. L. et al. Age-specific breast cancer risk by body mass index and familial risk: prospective family study cohort (ProF-SC). Breast cancer research : BCR 20, 132, doi:10.1186/s13058-018-1056-1 (2018).

146 Kehm, R. et al. Recreational physical activity and breast cancer risk: a cohort study of women selected for familial and genetic risk. . Cancer Res 80, 116-125 (2020).

147 Chlebowski, R. T. et al. Dietary Modification and Breast Cancer Mortality: LongTerm Follow-Up of the Women's Health Initiative Randomized Trial. J Clin Oncol, JCO1900435, doi:10.1200/JCO.19.00435 (2020). 
148 Chlebowski, R. T. et al. Ethnicity and breast cancer: factors influencing differences in incidence and outcome. Journal of the National Cancer Institute 97, 439-448, doi:10.1093/jnci/dji064 (2005).

149 Li, C. I., Malone, K. E. \& Daling, J. R. Differences in breast cancer hormone receptor status and histology by race and ethnicity among women 50 years of age and older. Cancer Epidemiol Biomarkers Prev 11, 601-607 (2002).

150 Millikan, R. C. et al. Epidemiology of basal-like breast cancer. Breast cancer research and treatment 109, 123-139, doi:10.1007/s10549-007-9632-6 (2008).

151 Pharoah, P. \& Ponder, B. in Genes and Common Diseases: Genetics in Modern Medicine (eds A. Wright \& N. Hastie) 224-232 (Cambridge University Press, 2007).

152 Banegas, M. P. et al. Projecting Individualized Absolute Invasive Breast Cancer Risk in US Hispanic Women. Journal of the National Cancer Institute 109, doi:10.1093/jnci/djw215 (2017).

153 Gail, M. H. et al. Projecting individualized absolute invasive breast cancer risk in African American women. Journal of the National Cancer Institute 99, 1782-1792, doi:10.1093/jnci/djm223 (2007).

154 Matsuno, R. K. et al. Projecting individualized absolute invasive breast cancer risk in Asian and Pacific Islander American women. Journal of the National Cancer Institute 103, 951-961, doi:10.1093/jnci/djr154 (2011).

155 Cintolo-Gonzalez, J. A. et al. Breast cancer risk models: a comprehensive overview of existing models, validation, and clinical applications. Breast cancer research and treatment 164, 263-284, doi:10.1007/s10549-017-4247-z (2017).

156 Tyrer, J., Duffy, S. W. \& Cuzick, J. A breast cancer prediction model incorporating familial and personal risk factors. Stat Med 23, 1111-1130, doi:10.1002/sim.1668 (2004).

157 Tice, J. A. et al. Using clinical factors and mammographic breast density to estimate breast cancer risk: development and validation of a new predictive model. Ann Intern Med 148, 337-347, doi:10.7326/0003-4819-148-5-200803040-00004 (2008).

158 Terry, M. B. et al. 10-year performance of four models of breast cancer risk: a validation study. The Lancet. Oncology 20, 504-517, doi:10.1016/S14702045(18)30902-1 (2019).

159 Rosner, B. \& Colditz, G. A. Nurses' health study: log-incidence mathematical model of breast cancer incidence. Journal of the National Cancer Institute 88, 359-364, doi:10.1093/jnci/88.6.359 (1996).

160 Parmigiani, G., Berry, D. \& Aguilar, O. Determining carrier probabilities for breast cancer-susceptibility genes BRCA1 and BRCA2. Am J Hum Genet 62, 145-158, doi:10.1086/301670 (1998).

161 https://tools.bcsc-scc.org/BC5yearRisk/intro.htm, T.-.

162 https://projects.iq.harvard.edu/bayesmendel/bayesmendel-r-package, B.-.

163 https://ccge.medschl.cam.ac.uk/boadicea/, B.-.

164 https://bcrisktool.cancer.gov/calculator.html, B.-.

165 http://www.ems-trials.org/riskevaluator/, I.-.

166 Gail, M. H. et al. Projecting individualized probabilities of developing breast cancer for white females who are being examined annually. Journal of the National Cancer Institute 81, 1879-1886, doi:10.1093/jnci/81.24.1879 (1989).

167 Berry, D. A., Parmigiani, G., Sanchez, J., Schildkraut, J. \& Winer, E. Probability of carrying a mutation of breast-ovarian cancer gene BRCA1 based on family history. Journal of the National Cancer Institute 89, 227-238, doi:10.1093/jnci/89.3.227 (1997). 
168 Antoniou, A. C., Pharoah, P. P., Smith, P. \& Easton, D. F. The BOADICEA model of genetic susceptibility to breast and ovarian cancer. Br J Cancer 91, 1580-1590, doi:10.1038/sj.bjc.6602175 (2004).

169 Antoniou, A. C. et al. A comprehensive model for familial breast cancer incorporating BRCA1, BRCA2 and other genes. Br J Cancer 86, 76-83, doi:10.1038/sj.bjc.6600008 (2002).

170 Petracci, E. et al. Risk factor modification and projections of absolute breast cancer risk. Journal of the National Cancer Institute 103, 1037-1048, doi:10.1093/jnci/djr172 (2011).

171 Gail, M. H., Anderson, W. F., Garcia-Closas, M. \& Sherman, M. E. Absolute risk models for subtypes of breast cancer. Journal of the National Cancer Institute 99, 1657-1659, doi:10.1093/jnci/djm228 (2007).

172 Colditz, G. A. \& Rosner, B. Cumulative risk of breast cancer to age 70 years according to risk factor status: data from the Nurses' Health Study. Am J Epidemiol 152, 950-964, doi:10.1093/aje/152.10.950 (2000).

173 Brentnall, A. R., Cuzick, J., Buist, D. S. M. \& Bowles, E. J. A. Long-term Accuracy of Breast Cancer Risk Assessment Combining Classic Risk Factors and Breast Density. JAMA Oncol 4, e180174, doi:10.1001/jamaoncol.2018.0174 (2018).

174 Bodian, C. A., Perzin, K. H. \& Lattes, R. Lobular neoplasia. Long term risk of breast cancer and relation to other factors. Cancer 78, 1024-1034, doi:10.1002/(SICI)10970142(19960901)78:5<1024::AID-CNCR12>3.0.CO;2-4 (1996).

175 Claus, E. B., Risch, N. \& Thompson, W. D. Autosomal dominant inheritance of earlyonset breast cancer. Implications for risk prediction. Cancer 73, 643-651, doi:10.1002/1097-0142(19940201)73:3<643::aid-cncr2820730323>3.0.co;2-5 (1994).

176 Amir, E. et al. Evaluation of breast cancer risk assessment packages in the family history evaluation and screening programme. J Med Genet 40, 807-814, doi:10.1136/jmg.40.11.807 (2003).

177 Brentnall, A. R. et al. A case-control evaluation of 143 single nucleotide polymorphisms for breast cancer risk stratification with classical factors and mammographic density. Int J Cancer 146, 2122-2129, doi:10.1002/ijc.32541 (2020).

178 Quante, A. S., Whittemore, A. S., Shriver, T., Strauch, K. \& Terry, M. B. Breast cancer risk assessment across the risk continuum: genetic and nongenetic risk factors contributing to differential model performance. Breast cancer research : BCR 14, R144, doi:10.1186/bcr3352 (2012).

179 van Veen, E. M. et al. Use of Single-Nucleotide Polymorphisms and Mammographic Density Plus Classic Risk Factors for Breast Cancer Risk Prediction. JAMA Oncol 4, 476-482, doi:10.1001/jamaoncol.2017.4881 (2018).

180 Cuzick, J. et al. Impact of a Panel of 88 Single Nucleotide Polymorphisms on the Risk of Breast Cancer in High-Risk Women: Results From Two Randomized Tamoxifen Prevention Trials. J Clin Oncol 35, 743-750, doi:10.1200/JCO.2016.69.8944 (2017).

181 Steyerberg, E. W. et al. Assessing the performance of prediction models: a framework for traditional and novel measures. Epidemiology 21, 128-138, doi:10.1097/EDE.0b013e3181c30fb2 (2010).

182 Louro, J. et al. A systematic review and quality assessment of individualised breast cancer risk prediction models. Br J Cancer 121, 76-85, doi:10.1038/s41416-0190476-8 (2019).

183 Endogenous, H. et al. Sex hormones and risk of breast cancer in premenopausal women: a collaborative reanalysis of individual participant data from seven 
prospective studies. The Lancet. Oncology 14, 1009-1019, doi:10.1016/S14702045(13)70301-2 (2013).

184 Terry, M. B., McDonald, J. A., Wu, H. C., Eng, S. \& Santella, R. M. Epigenetic Biomarkers of Breast Cancer Risk: Across the Breast Cancer Prevention Continuum. Adv Exp Med Biol 882, 33-68, doi:10.1007/978-3-319-22909-6_2 (2016).

185 Machella, N. et al. Double-strand breaks repair in lymphoblastoid cell lines from sisters discordant for breast cancer from the New York site of the BCFR. Carcinogenesis 29, 1367-1372, doi:10.1093/carcin/bgn140 (2008).

186 Phillips, K. A. et al. Transitioning to routine breast cancer risk assessment and management in primary care: what can we learn from cardiovascular disease? Aust $J$ Prim Health 22, 255-261, doi:10.1071/PY14156 (2016).

187 Collins, I. M. et al. iPrevent(R): a tailored, web-based, decision support tool for breast cancer risk assessment and management. Breast cancer research and treatment $\mathbf{1 5 6}$, 171-182, doi:10.1007/s10549-016-3726-y (2016).

188 Phillips, K. A. et al. Accuracy of estimates from the iPrevent breast cancer risk assessment and risk management tool. . JNCI-Cancer Spec (4), pkz066 (2019).

189 Lo, L. L. et al. The iPrevent Online Breast Cancer Risk Assessment and Risk Management Tool: Usability and Acceptability Testing. JMIR Form Res 2, e24, doi:10.2196/formative.9935 (2018).

190 Keogh, L. A. et al. Consumer and clinician perspectives on personalising breast cancer prevention information. Breast 43, 39-47, doi:10.1016/j.breast.2018.11.002 (2019).

191 DeSantis, C. E. et al. Breast cancer statistics, 2019. CA Cancer J Clin 69, 438-451, doi:10.3322/caac.21583 (2019).

192 Visvanathan, K. et al. Use of Endocrine Therapy for Breast Cancer Risk Reduction: ASCO Clinical Practice Guideline Update J Clin Oncol JCO1901472 (2019).

193 NCCN. National Comprehensive Cancer Network. Breast Cancer Risk Reduction. . (2019).

194 NICE, N. I. f. H. a. C. E. Familial breast cancer: Classification and care of people at risk of familial breast cancer and management of breast cancer and related risks in people with a family history of breast cancer. . (2017).

$195 \mathrm{Li}$, X. et al. Effectiveness of Prophylactic Surgeries in BRCA1 or BRCA2 Mutation Carriers: A Meta-analysis and Systematic Review. Clin Cancer Res 22, 3971-3981, doi:10.1158/1078-0432.CCR-15-1465 (2016).

196 Hartmann, L. C. et al. Efficacy of bilateral prophylactic mastectomy in women with a family history of breast cancer. $N$ Engl J Med 340, 77-84, doi:10.1056/NEJM199901143400201 (1999).

197 Carbine, N. E., Lostumbo, L., Wallace, J. \& Ko, H. Risk-reducing mastectomy for the prevention of primary breast cancer. The Cochrane database of systematic reviews $\mathbf{4}$, CD002748, doi:10.1002/14651858.CD002748.pub4 (2018).

198 Jakub, J. W. et al. Oncologic Safety of Prophylactic Nipple-Sparing Mastectomy in a Population With BRCA Mutations: A Multi-institutional Study. JAMA Surg 153, 123 129, doi:10.1001/jamasurg.2017.3422 (2018).

199 Metcalfe, K. et al. International trends in the uptake of cancer risk reduction strategies in women with a BRCA1 or BRCA2 mutation. Br J Cancer 121, 15-21, doi:10.1038/s41416-019-0446-1 (2019).

200 Rebbeck, T. R., Kauff, N. D. \& Domchek, S. M. Meta-analysis of risk reduction estimates associated with risk-reducing salpingo-oophorectomy in BRCA1 or BRCA2 mutation carriers. Journal of the National Cancer Institute 101, 80-87, doi:10.1093/jnci/djn442 (2009). 
201 Heemskerk-Gerritsen, B. A. et al. Breast cancer risk after salpingo-oophorectomy in healthy BRCA1/2 mutation carriers: revisiting the evidence for risk reduction. Journal of the National Cancer Institute 107, doi:10.1093/jnci/djv033 (2015).

202 Terry, M. B. et al. Risk-Reducing Oophorectomy and Breast Cancer Risk Across the Spectrum of Familial Risk. Journal of the National Cancer Institute 111, 331-334, doi:10.1093/jnci/djy182 (2019).

203 Kotsopoulos, J. et al. Bilateral Oophorectomy and Breast Cancer Risk in BRCA1 and BRCA2 Mutation Carriers. Journal of the National Cancer Institute 109, doi:10.1093/jnci/djw177 (2017).

204 Mai, P. L. et al. Risk-Reducing Salpingo-Oophorectomy and Breast Cancer Risk Reduction in the Gynecologic Oncology Group Protocol-0199 (GOG-0199) JNCI Cancer Spectrum https://doi.org/10.1093/jncics/pkz075 (2019).

205 Milne, R. L. \& Antoniou, A. C. Modifiers of breast and ovarian cancer risks for BRCA1 and BRCA2 mutation carriers. Endocr Relat Cancer 23, T69-84, doi:10.1530/ERC-16-0277 (2016).

206 Cuzick, J. et al. Selective oestrogen receptor modulators in prevention of breast cancer: an updated meta-analysis of individual participant data. Lancet 381, 18271834, doi:10.1016/S0140-6736(13)60140-3 (2013).

207 Cuzick, J. et al. Tamoxifen for prevention of breast cancer: extended long-term follow-up of the IBIS-I breast cancer prevention trial. The Lancet. Oncology 16, 6775, doi:10.1016/S1470-2045(14)71171-4 (2015).

208 Nelson, H. D., Smith, M. E., Griffin, J. C. \& Fu, R. Use of medications to reduce risk for primary breast cancer: a systematic review for the U.S. Preventive Services Task Force. Ann Intern Med 158, 604-614, doi:10.7326/0003-4819-158-8-20130416000005 (2013).

209 Skandarajah, A. R. et al. Patient and medical barriers preclude uptake of tamoxifen preventative therapy in women with a strong family history. Breast 32, 93-97, doi:10.1016/j.breast.2017.01.002 (2017).

210 Vogel, V. G. et al. Update of the National Surgical Adjuvant Breast and Bowel Project Study of Tamoxifen and Raloxifene (STAR) P-2 Trial: Preventing breast cancer. Cancer Prev Res (Phila) 3, 696-706, doi:10.1158/1940-6207.CAPR-10-0076 (2010).

211 Freedman, A. N. et al. Benefit/risk assessment for breast cancer chemoprevention with raloxifene or tamoxifen for women age 50 years or older. J Clin Oncol 29, 23272333, doi:10.1200/JCO.2010.33.0258 (2011).

212 Cuzick, J. et al. Use of anastrozole for breast cancer prevention (IBIS-II): long-term results of a randomised controlled trial. Lancet 395, 117-122, doi:10.1016/S01406736(19)32955-1 (2020).

213 Cuzick, J. et al. Anastrozole for prevention of breast cancer in high-risk postmenopausal women (IBIS-II): an international, double-blind, randomised placebo-controlled trial. Lancet 383, 1041-1048, doi:10.1016/S0140-6736(13)622928 (2014).

214 Goss, P. E. et al. Exemestane for breast-cancer prevention in postmenopausal women. N Engl J Med 364, 2381-2391, doi:10.1056/NEJMoa1103507 (2011).

215 Noonan, S. et al. A Survey among Breast Cancer Specialists on the Low Uptake of Therapeutic Prevention with Tamoxifen or Raloxifene. Cancer Prev Res (Phila) 11, 38-43, doi:10.1158/1940-6207.CAPR-17-0162 (2018).

216 Collins, I. M. et al. Preventing breast and ovarian cancers in high-risk BRCA1 and BRCA2 mutation carriers. Med J Aust 199, 680-683, doi:10.5694/mja13.10848 (2013). 
217 Collins, I. M. et al. Assessing and managing breast cancer risk: clinicians' current practice and future needs. Breast 23, 644-650, doi:10.1016/j.breast.2014.06.014 (2014).

218 Keogh, L. A., Hopper, J. L., Rosenthal, D. \& Phillips, K. A. Australian clinicians and chemoprevention for women at high familial risk for breast cancer. Hered Cancer Clin Pract 7, 9, doi:10.1186/1897-4287-7-9 (2009).

219 Smith, S. G. et al. Prescribing tamoxifen in primary care for the prevention of breast cancer: a national online survey of GPs' attitudes. Br J Gen Pract 67, e414-e427, doi:10.3399/bjgp17X689377 (2017).

220 Smith, S. G. et al. Factors affecting uptake and adherence to breast cancer chemoprevention: a systematic review and meta-analysis. Ann Oncol 27, 575-590, doi:10.1093/annonc/mdv590 (2016).

221 Fisher, B. et al. Tamoxifen for prevention of breast cancer: report of the National Surgical Adjuvant Breast and Bowel Project P-1 Study. Journal of the National Cancer Institute 90, 1371-1388, doi:10.1093/jnci/90.18.1371 (1998).

222 Donnelly, L. S. et al. Uptake of tamoxifen in consecutive premenopausal women under surveillance in a high-risk breast cancer clinic. Br J Cancer 110, 1681-1687, doi:10.1038/bjc.2014.109 (2014).

223 Bober, S. L., Hoke, L. A., Duda, R. B., Regan, M. M. \& Tung, N. M. Decisionmaking about tamoxifen in women at high risk for breast cancer: clinical and psychological factors. J Clin Oncol 22, 4951-4957, doi:10.1200/JCO.2004.05.192 (2004).

224 Cuzick, J. et al. First results from the International Breast Cancer Intervention Study (IBIS-I): a randomised prevention trial. Lancet 360, 817-824, doi:10.1016/s01406736(02)09962-2 (2002).

225 Heisey, R., Pimlott, N., Clemons, M., Cummings, S. \& Drummond, N. Women's views on chemoprevention of breast cancer: qualitative study. Can Fam Physician 52, 624-625 (2006).

226 Kuderer, N. M. \& Peppercorn, J. CYP2D6 testing in breast cancer: ready for prime time? Oncology (Williston Park) 23, 1223-1232 (2009).

227 Decensi, A. et al. A randomized trial of low-dose tamoxifen on breast cancer proliferation and blood estrogenic biomarkers. Journal of the National Cancer Institute 95, 779-790, doi:10.1093/jnci/95.11.779 (2003).

228 DeCensi, A. et al. Randomized Placebo Controlled Trial of Low-Dose Tamoxifen to Prevent Local and Contralateral Recurrence in Breast Intraepithelial Neoplasia. J Clin Oncol 37, 1629-1637, doi:10.1200/JCO.18.01779 (2019).

229 US National Library of Medicine. ClinicalTrials.gov, h. c. g. c. s. N. (2009).

230 Rojas, L. B. \& Gomes, M. B. Metformin: an old but still the best treatment for type 2 diabetes. Diabetol Metab Syndr 5, 6, doi:10.1186/1758-5996-5-6 (2013).

231 Bodmer, M., Meier, C., Krahenbuhl, S., Jick, S. S. \& Meier, C. R. Long-term metformin use is associated with decreased risk of breast cancer. Diabetes Care 33, 1304-1308, doi:10.2337/dc09-1791 (2010).

232 EU Clinical Trials Register, h. w. c. e. c.-s. s. q. e. n.-.-. (2010).

233 Boissier, S. et al. Bisphosphonates inhibit breast and prostate carcinoma cell invasion, an early event in the formation of bone metastases. Cancer Res 60, 2949-2954 (2000).

234 Chlebowski, R. T. et al. Oral bisphosphonate use and breast cancer incidence in postmenopausal women. J Clin Oncol 28, 3582-3590, doi:10.1200/JCO.2010.28.2095 (2010).

235 Daubine, F., Le Gall, C., Gasser, J., Green, J. \& Clezardin, P. Antitumor effects of clinical dosing regimens of bisphosphonates in experimental breast cancer bone 
metastasis. Journal of the National Cancer Institute 99, 322-330, doi:10.1093/jnci/djk054 (2007).

236 van der Pluijm, G. et al. Bisphosphonates inhibit the adhesion of breast cancer cells to bone matrices in vitro. The Journal of clinical investigation 98, 698-705, doi:10.1172/JCI118841 (1996).

237 Early Breast Cancer Trialists' Collaborative, G. Adjuvant bisphosphonate treatment in early breast cancer: meta-analyses of individual patient data from randomised trials. Lancet 386, 1353-1361, doi:10.1016/S0140-6736(15)60908-4 (2015).

238 Dhesy-Thind, S. et al. Use of Adjuvant Bisphosphonates and Other Bone-Modifying Agents in Breast Cancer: A Cancer Care Ontario and American Society of Clinical Oncology Clinical Practice Guideline. J Clin Oncol 35, 2062-2081, doi:10.1200/JCO.2016.70.7257 (2017).

239 Gnant, M., Harbeck, N. \& Thomssen, C. St. Gallen/Vienna 2017: A Brief Summary of the Consensus Discussion about Escalation and De-Escalation of Primary Breast Cancer Treatment. Breast Care (Basel) 12, 102-107, doi:10.1159/000475698 (2017).

240 Vestergaard, P., Fischer, L., Mele, M., Mosekilde, L. \& Christiansen, P. Use of bisphosphonates and risk of breast cancer. Calcif Tissue Int 88, 255-262, doi:10.1007/s00223-011-9463-7 (2011).

241 EU Clinical Trials Register, h. w. c. e. c.-s. s. q.-.-. (2009).

242 Moon, R. C. et al. N-(4-Hydroxyphenyl)retinamide, a new retinoid for prevention of breast cancer in the rat. Cancer Res 39, 1339-1346 (1979).

243 Veronesi, U. et al. Randomized trial of fenretinide to prevent second breast malignancy in women with early breast cancer. Journal of the National Cancer Institute 91, 1847-1856, doi:10.1093/jnci/91.21.1847 (1999).

$244 \mathrm{Xu}$, L. et al. Tamoxifen and risk of contralateral breast cancer among women with inherited mutations in BRCA1 and BRCA2: a meta-analysis. Breast Cancer 22, 327 334, doi:10.1007/s12282-015-0619-6 (2015).

245 Phillips, K. A. et al. Tamoxifen and risk of contralateral breast cancer for BRCA1 and BRCA2 mutation carriers. J Clin Oncol 31, 3091-3099, doi:10.1200/JCO.2012.47.8313 (2013).

246 Nolan, E. et al. RANK ligand as a potential target for breast cancer prevention in BRCA1-mutation carriers. Nat Med 22, 933-939, doi:10.1038/nm.4118 (2016).

247 Nolan, E., Lindeman, G. J. \& Visvader, J. E. Out-RANKing BRCA1 in Mutation Carriers. Cancer Res 77, 595-600, doi:10.1158/0008-5472.CAN-16-2025 (2017).

248 EU Clinical Trials Register, h. w. c. e. c.-s. t.-.-A. (2018).

249 Poole, A. J. et al. Prevention of Brca1-mediated mammary tumorigenesis in mice by a progesterone antagonist. Science 314, 1467-1470, doi:10.1126/science.1130471 (2006).

250 US National Library of Medicine. ClinicalTrials.gov, h. c. g. c. s. N. (2015).

251 Lu, L., Shi, L., Zeng, J. \& Wen, Z. Aspirin as a potential modality for the chemoprevention of breast cancer: A dose-response meta-analysis of cohort studies from 857,831 participants. Oncotarget 8, 40389-40401, doi:10.18632/oncotarget.16315 (2017).

252 de Pedro, M. et al. Effect of COX-2 inhibitors and other non-steroidal inflammatory drugs on breast cancer risk: a meta-analysis. Breast cancer research and treatment 149, 525-536, doi:10.1007/s10549-015-3267-9 (2015).

$253 \mathrm{Kehm}$, R. D. et al. Regular use of aspirin and other non-steroidal anti-inflammatory drugs and breast cancer risk for women at familial or genetic risk: a cohort study. Breast cancer research : BCR 21, 52, doi:10.1186/s13058-019-1135-y (2019). 
254 Gierach, G. L. et al. Nonsteroidal anti-inflammatory drugs and breast cancer risk in the National Institutes of Health-AARP Diet and Health Study. Breast cancer research : BCR 10, R38, doi:10.1186/bcr2089 (2008).

255 Marshall, S. F. et al. Nonsteroidal anti-inflammatory drug use and breast cancer risk by stage and hormone receptor status. Journal of the National Cancer Institute $\mathbf{9 7 ,}$ 805-812, doi:10.1093/jnci/dji140 (2005).

256 Terry, M. B. et al. Association of frequency and duration of aspirin use and hormone receptor status with breast cancer risk. JAMA 291, 2433-2440, doi:10.1001/jama.291.20.2433 (2004).

257 Cuzick, J. et al. Long-term results of tamoxifen prophylaxis for breast cancer--96month follow-up of the randomized IBIS-I trial. Journal of the National Cancer Institute 99, 272-282, doi:10.1093/jnci/djk049 (2007).

258 Unsworth, A., Anderson, R. \& Britt, K. Stromal fibroblasts and the immune microenvironment: partners in mammary gland biology and pathology? J Mammary Gland Biol Neoplasia 19, 169-182, doi:10.1007/s10911-014-9326-8 (2014).

259 Visvader, J. E. \& Stingl, J. Mammary stem cells and the differentiation hierarchy: current status and perspectives. Genes Dev 28, 1143-1158, doi:10.1101/gad.242511.114 (2014).

260 Gil Del Alcazar, C. R. et al. Immune Escape in Breast Cancer During In Situ to Invasive Carcinoma Transition. Cancer Discov 7, 1098-1115, doi:10.1158/21598290.CD-17-0222 (2017).

261 Cossart, Y. E. The rise and fall of infectious diseases: Australian perspectives, 19142014. Med J Aust 201, S11-14, doi:10.5694/mja14.00112 (2014).

262 US National Library of Medicine. ClinicalTrials.gov, h. c. g. c. s. N. (2004).

263 US National Library of Medicine. ClinicalTrials.gov, h. c. g. c. s. N. (2017).

264 EU Clinical Trials Register, h. w. c. e. c.-s. s. q.-.-. (2016).

265 US National Library of Medicine. ClinicalTrials.gov, h. c. g. c. s. N. (2016).

266 Australia NewZealand Clinical Trials registry, h. w. a. o. a. T. R. T. a. A. (2014).

267 Collaborative Group on Hormonal Factors in Breast, C. Breast cancer and hormonal contraceptives: collaborative reanalysis of individual data on 53297 women with breast cancer and 100239 women without breast cancer from 54 epidemiological studies. Lancet 347, 1713-1727, doi:10.1016/s0140-6736(96)90806-5 (1996).

268 Morch, L. S. et al. Contemporary Hormonal Contraception and the Risk of Breast Cancer. N Engl J Med 377, 2228-2239, doi:10.1056/NEJMoa1700732 (2017).

269 https://www.aihw.gov.au/reports/overweight-obesity/overweight-and-obesity-aninteractive-insight/contents/prevalence.

270 Provenzano, P. P. et al. Collagen density promotes mammary tumor initiation and progression. BMC Med 6, 11, doi:10.1186/1741-7015-6-11 (2008).

271 Alowami, S., Troup, S., Al-Haddad, S., Kirkpatrick, I. \& Watson, P. H. Mammographic density is related to stroma and stromal proteoglycan expression. Breast cancer research : BCR 5, R129-135, doi:10.1186/bcr622 (2003).

272 Cho, A., Howell, V. M. \& Colvin, E. K. The Extracellular Matrix in Epithelial Ovarian Cancer - A Piece of a Puzzle. Front Oncol 5, 245, doi:10.3389/fonc.2015.00245 (2015).

273 Provenzano, P. P. \& Keely, P. J. Mechanical signaling through the cytoskeleton regulates cell proliferation by coordinated focal adhesion and Rho GTPase signaling. J Cell Sci 124, 1195-1205, doi:10.1242/jcs.067009 (2011).

274 Lisanti, M. P. et al. JNK1 stress signaling is hyper-activated in high breast density and the tumor stroma: connecting fibrosis, inflammation, and stemness for cancer prevention. Cell Cycle 13, 580-599, doi:10.4161/cc.27379 (2014). 
275 Dushyanthen, S. et al. Relevance of tumor-infiltrating lymphocytes in breast cancer. BMC Med 13, 202, doi:10.1186/s12916-015-0431-3 (2015).

276 Tower, H., Ruppert, M. \& Britt, K. The Immune Microenvironment of Breast Cancer Progression. Cancers 11, 1375 (2019).

277 Simon, T. \& Bromberg, J. S. Regulation of the Immune System by Laminins. Trends Immunol 38, 858-871, doi:10.1016/j.it.2017.06.002 (2017).

278 Lu, P., Takai, K., Weaver, V. M. \& Werb, Z. Extracellular matrix degradation and remodeling in development and disease. Cold Spring Harb Perspect Biol 3, doi:10.1101/cshperspect.a005058 (2011).

279 Hallmann, R. et al. The regulation of immune cell trafficking by the extracellular matrix. Curr Opin Cell Biol 36, 54-61, doi:10.1016/j.ceb.2015.06.006 (2015).

280 Kajita, M. \& Fujita, Y. EDAC: Epithelial defence against cancer-cell competition between normal and transformed epithelial cells in mammals. J Biochem 158, 15-23, doi:10.1093/jb/mvv050 (2015).

281 Althuis, M. D. et al. Hormonal content and potency of oral contraceptives and breast cancer risk among young women. Br J Cancer 88, 50-57, doi:10.1038/sj.bjc.6600691 (2003).

282 Collaborative Group on Hormonal Factors in Breast Cancer. Breast cancer and hormone replacement therapy: collaborative reanalysis of data from 51 epidemiological studies of 52,705 women with breast cancer and 108,411 women without breast cancer. Collaborative Group on Hormonal Factors in Breast Cancer. Lancet 350, 1047-1059 (1997).

283 Hunter, D. J. et al. Oral contraceptive use and breast cancer: a prospective study of young women. Cancer Epidemiol Biomarkers Prev 19, 2496-2502, doi:10.1158/10559965.EPI-10-0747 (2010).

284 Beral, V. \& Million Women Study, C. Breast cancer and hormone-replacement therapy in the Million Women Study. Lancet 362, 419-427 (2003).

285 Jones, J., Mosher, W. \& Daniels, K. Current contraceptive use in the United States, 2006-2010, and changes in patterns of use since 1995. (2012).

286 Statistics., N. C. f. H. National Survey of Family Growth (NSFG): Summary of design and data collection methods. . (Hyattsville, MD., 2013-2015 ).

287 Rossouw, J. E. et al. Risks and benefits of estrogen plus progestin in healthy postmenopausal women: principal results From the Women's Health Initiative randomized controlled trial. JAMA 288, 321-333, doi:10.1001/jama.288.3.321 (2002).

288 Chlebowski, R. T. et al. Breast Cancer After Use of Estrogen Plus Progestin and Estrogen Alone: Analyses of Data From 2 Women's Health Initiative Randomized Clinical Trials. JAMA Oncol 1, 296-305, doi:10.1001/jamaoncol.2015.0494 (2015).

289 Chlebowski, R. T. et al. Influence of estrogen plus progestin on breast cancer and mammography in healthy postmenopausal women: the Women's Health Initiative Randomized Trial. JAMA 289, 3243-3253, doi:10.1001/jama.289.24.3243 (2003).

290 Chlebowski, R. T. et al. in San Antonio Breast Cancer Symposium ABSTRACT NUMBER GS5-00

(2019). 